INSTITUTO DE PESQUISAS ENERGÉTICAS E NUCLEARES

Autarquia associada à Universidade de São Paulo

\title{
EFEITOS DA TERAPIA COM LASER BAIXA POTÊNCIA EM MELANOMA: ENSAIOS IN VITRO
}

\section{ANTONIO JOSE DA SILVA SANTOS}

Dissertação apresentada como parte dos requisitos para obtenção do Grau de Mestre em Ciências na Área de Tecnologia Nuclear - Materiais

Orientadora:

Profa. Dra. Martha Simões Ribeiro

Versão Corrigida

Versão Original se encontra disponível no IPEN

São Paulo

2013 
Dedico este trabalho à minha avó Dínísía Louzado Reis, uma guerreira, pela coragem e serenidade com que sempre enfrentou as difículdades da vida. 


\section{AGRADECIMENTOS}

Aos meus pais Geraldo Simões dos Santos e Joana Maria da Silva Santos que, desde criança, sempre nos incentivaram a estudar e não mediram esforços em prol da nossa feicidade e apoio em todos os momentos.

Aos meus irmãos Dionísia, Juscelino e Fernanda pela amizade, incentivo e cumplicidade que foram muito importantes nesta etapa da minha vida.

À minha orientadora Profa. Dra. Martha Simões Ribeiro, pela confiança, amizade e muita paciência na execução deste trabalho.

À Profa. Dra. Maria Lucia Zaidan Dagli, que gentilmente nos cedeu a linhagem B16F10 utilizada neste estudo.

À Profa. Dra. Cristiane Miranda França, pela colaboração na realização deste trabalho e amizade.

Aos meus colegas e amigos do Laboratório de Fotoprocessos nãotérmicos em Biociências do Centro de Lasers e Aplicações: Renato Araujo Prates, Ilka Kato, Luiz Cláudio Suzuki, Rosa Maria Machado de Sena, Caetano Padial Sabino, Tânia Mateus Yoshimura e Débora Picanço Aureliano pela convivência enriquecedora. 
Aos meus colegas do Centro de Lasers e Aplicações: Letícia Bonfante Sicchieri, Danilo Mariano da Silva, Renato Renato Juliani Ribamar Vieira, Matheus Tunes, Ana Claudia Ballet de Cara, Fábio Juliano da Silva Lopes, Eliane Gonçalves Larroza e Walter Morinobu Nakaema.

Aos funcionários, colegas e professores do CLA e IPEN.

Aos funcionários e colegas de Laboratório da Universidade Nove de Julho.

A minha querida amiga e colega Fernanda Martins Tonon pelos momentos de descontração e aprendizado na Fisioterapia Oncológica.

E finalmente, agradeço ao IPEN, ao CLA, à USP, ao CNPq e CAPES por terem viabilizado o meu mestrado. 
"O que conhecemos de nós mesmos não é senão superfície. A pronfundidade permanece-nos em grande parte oculta e só Deus a confece" 


\section{EFEITOS DA TERAPIA COM LASER DE BAIXA POTÊNCIA EM \\ MELANOMA. ENSAIOS IN VITRO}

\section{ANTONIO JOSE DA SILVA SANTOS}

\section{RESUMO}

Embora a terapia com uso de laser de baixa potência (TLBP) seja uma modalidade terapêutica amplamente estudada no meio científico, sua aplicação na clínica médica ainda gera controvérsias, já que a literatura reporta que a TLBP é capaz de promover a proliferação e diferenciação de células tumorais. O objetivo deste estudo foi avaliar os efeitos da TLBP no crescimento celular usando como modelo a linhagem B16F10 de melanoma murino em estado de homeostase e estado redox, além de verificar o comportamento quimiotáxico da linhagem B16F10 por meio do ensaio de migração transwell em resposta à TLBP em diferentes densidades de energia. Foram montados cinco grupos experimentais utilizando um laser de emissão vermelha em $\lambda=660 \mathrm{~nm}$ : Grupo controle (GC) onde nenhuma irradiação foi realizada; $G 30\left(30 \mathrm{~J} / \mathrm{cm}^{2}\right) ; \mathrm{G} 60$ $\left(60 \mathrm{~J} / \mathrm{cm}^{2}\right) ;$ G90 $\left(90 \mathrm{~J} / \mathrm{cm}^{2}\right) ;$ G120 $\left(120 \mathrm{~J} / \mathrm{cm}^{2}\right) ;$ G150 $\left(150 \mathrm{~J} / \mathrm{cm}^{2}\right)$, com as respectivas doses utilizadas. Todos os experimentos foram realizados em triplicata e os resultados obtidos foram submetidos à análise estatística. Sob as condições experimentais deste estudo, nossos resultados mostram que a TLBP neste comprimento de onda não promoveu mudanças no metabolismo celular nos tempos de 48 h e 72 h, independente do estado nutricional. Foi possível observar mudança no padrão de comportamento quimiotáxico da linhagem celular B16F10 irradiadas com laser de emissão vermelha. 


\title{
EFECTS OF LOW LEVEL LASER THERAPY ON MELANOMA \\ AN IN VITRO STUDY
}

\section{ANTONIO JOSE DA SILVA SANTOS}

\begin{abstract}
The low power lasers (TLBP) is a therapeutic modality widely studied in scientific field, its application in clinical medicine still generates many conflicts since literature reports proliferation in cancer cells. The objective of this study was to evaluate the effects of TLBP on cell growth using as model the line B16F10 in state of homeostasis and redox state and investigate the chemotactic behavior of $\mathrm{B} 16 \mathrm{~F} 10$ lineage through transwell migration assay in response to TLBP in different energy densities. For this purpose five experimental groups were assembled using a laser emission at $\lambda=660 \mathrm{~nm}$ : control group (G0) where no irradiation was performed; G30 $\left(30 \mathrm{~J} / \mathrm{cm}^{2}\right), \mathrm{G} 60$ $\left(60 \mathrm{~J} / \mathrm{cm}^{2}\right), \quad$ G90 $\left(90 \mathrm{~J} / \mathrm{cm}^{2}\right) ; \operatorname{G120}\left(120 \mathrm{~J} / \mathrm{cm}^{2}\right) ; \mathrm{G150}\left(150 \mathrm{~J} / \mathrm{cm}^{2}\right)$ with the respective doses used. All experiments were performed in triplicate and the results were statistically analyzed. Under the experimental conditions of this study, our results show that TLBP did not induced changes in cellular metabolism that influence proliferation at $48 \mathrm{~h}$ and $72 \mathrm{~h}$, independent nutritional status. It was possible to observe changes in behavior pattern chemotactic of cell line B16F10 with TLBP at red emission.
\end{abstract}




\section{LISTA DE FIGURAS}

Figura 1 - Fluxograma mostrando um esquma simplificado da base molecular do câncer . 18

Figura 2 - Estimativas do número de casos novos de câncer para o ano de 2012

Figura 3 - Ilustração do processo de angiogêneses induzido por células tumorais

Figura 4 - llustração do processo de invasão, angiogêneses, disseminação hematogênica e a formação de sítios metastáticos. 24

Figura 5 - Sequência do processo de descongelamento e expansão da linhagem celular B16F10 de melanoma murino.

Figura 6 - Linhagem celular de melanoma B16F10 vista em microscópio invertido (aumento original: 20X).

Figura 7 - Sequência do processo de repique e subcultivo da linhagem celular B16F10 de melanoma murino.

Figura 8 - Sequência do processo de contagem de células viáveis da linhagem celular B16F10 de melanoma murino.

Figura 9 - Distribuição dos poços experimentais (vermelho); em amarelo, poços contendo PBS.

Figura 10 - Máscara escura utilizada durante o processo de irradiação.

Figura 11 - Aparato utilizado para fixar a ponteira do laser em contato constante com o fundo do poço durante o tempo de irradiação.

Figura 12 - Sequência experimental do ensaio de viabilidade celular por meio da técnica de MTT.

Figura 13 - Ilustra o início da técnica, sobre a membrana superior estão as células em estudo.

Figura 14 - llustra o final da técnica onde no compartimento inferior é possível observar as células que migraram.

Figura 15 - Sequência experimental do ensaio de migração celular por meio da técnica de transwell.

Figura 16 - Leitura do ensaio imunoenzimático (ELISA) para dosagem de VEGF em espectrofotômetro. 
Figura 17 - Valores da média e desvio padrão correspondentes à atividade mitocondrial medida pela densidade óptica (DO) para as células de melanoma murino B16F10 cultivadas com déficit nutricional (meio RPMl suplementado com 5\% SFB).

Figura 18 - Valores da média e desvio padrão correspondentes à atividade mitocondrial medida pela densidade óptica (DO) para as células de melanoma murino B16F10 cultivadas sem déficit nutricional meio RPMI suplementado com $10 \% . S F B$.

Figura 19 - Valores da média e desvio padrão correspondente à atividade mitocondrial medida pela densidade óptica (DO) para as células de melanoma murino B16F10 para as diferentes dosagens utilizadas no momento $24 \mathrm{~h}$.

Figura 20 - Valores da média e desvio padrão correspondente à atividade mitocondrial medida pela densidade óptica (DO) para as células de melanoma murino B16F10 para as diferentes dosagens utilizadas no momento $48 \mathrm{~h}$....... 50 Figura 21 - Valores da média e desvio padrão correspondente à atividade mitocondrial medida pela densidade óptica (DO) para as células de melanoma murino B16F10 para as diferentes dosagens utilizadas no momento $72 \mathrm{~h}$....... 51 Figura 22 - Fotomicrografia de células de melanoma B16F10 que migraram observadas ao microscópio invertido. A seta aponta para células que migraram em busca do nutriente (aumento original: 600x).

Figura 23 - Valores da média \pm erro padrão da medida correspondente ao número de células que migraram através do matrigel.

Figura 24 - Expressão de VEGF em linhagem de meleanoma murino (B16F10) irradiadas com diferentes densidadede energia. 


\section{LISTA DE TABELA}

Tabela 1 - Parâmetros utilizado durante as irradiações com laser. 36 


\section{LISTA DE SIGLAS E ABREVIATURAS}

CLA Centro de Lasers e Aplicações

DMSO Dimetilsulfóxido

He-Ne Hélio-neônio

INCA Instituto Nacional do Câncer

IPEN Instituto de Pesquisas Energéticas e Nucleares

MTT Brometo de 3-(4,5-dimetiltiazol-2-il)-2,5-difeniltetrazólio

PBSA Solução tampão fostato salina sem cálcio e magnésio

SFB Soro fetal bovino

TLBP Terapia com laser de baixa potência

USP Universidade de São Paulo 


\section{LISTA DE SÍMBOLOS E UNIDADES}

$\mathrm{cm}^{2}$ : centímetros quadrados

$\mathrm{CO}_{2}$ : dióxido de carbono

$\mathrm{nm}$ : nanometro

mm: milímetro

h: hora

$\mu \mathrm{m}$ : micrometro

$\mathrm{mW}$ : miliwatt

$\mathrm{J} \mathrm{cm}^{-2}$ : Joule por centímetros quadrados

cm: centímetro

${ }^{\circ} \mathrm{C}$ : graus Celsius

s: segundo

$\mu \mathrm{L}:$ microlitro

mL: mililitro

$\kappa:$ Comprimento de onda 


\section{SUMÁRIO}

1 INTRODUÇÃO

2 OBJETIVOS 16

2.1 OBJETIVOS ESPECÍFICOS 16

3 REVISÃO DA LITERATURA $\quad 17$

$\begin{array}{ll}\text { 3.1 MELANOMA } & 17\end{array}$

3.2 ANGIOGÊNESE $\quad 21$

3.3 FATOR DE CRESCIMENTO ENDOTELIAL VASCULAR (VEGF) 22

3.4 METÁSTASE $\quad 23$

3.5 FOTOBIOMODULAÇÃO 25

4 MATERIAIS E MÉTODOS 30

$\begin{array}{ll}\text { 4.1 CULTIVO CELULAR } & 30\end{array}$

4.2 VIABILIDADE CELULAR 33

4.4 EQUIPAMENTO LASER 35

4.5 CURVAS DE VIABILIDADE CELULAR 38

4.3 ENSAIO DE MIGRAÇÃO TRANSWELL 39

4.6 ENSAIO IMUNOENZIMÁTICO PARA DOSAGEM DE VEGF 41

4.7 ANÁLISE ESTATÍSTICA $\quad 44$

5 RESULTADOS E DISCUSSÃO 45

6 CONCLUSÕES $\quad 56$

7 REFERÊNCIAS BIBLIOGRÁFICAS 


\section{INTRODUÇÃO}

As neoplasias malignas representam a segunda causa de morte nas capitais brasileiras, segundo o Instituto Nacional de Câncer (INCA). Para o ano de 2012 são esperados aproximadamente 520.000 novos casos de câncer. Dentre estes, os tumores cutâneos que são classificados em dois grandes grupos: os tumores epidermóides, também conhecidos como tumores não melanoma que são os de maior incidência na população brasileira e os tumores tipo melanoma, seguidos pelos tumores de próstata e pulmão no sexo masculino e os tumores de mama e de colo do útero no sexo feminino (1).

O processo neoplásico é definido como um conjunto de alterações genéticas que resultam na perda dos controles normais de proliferação celular e da interação célula-célula. A ativação aberrante dos proto-oncogenes em conjunto com a inativação dos genes supressores de tumor representam os fundamentos deste processo $(2,3)$.

O melanoma cutâneo é uma lesão maligna que acomete os melanócitos, células produtoras de melanina, substância responsável pela coloração e defesa da pele contra a radiação ultravioleta. $O$ tumor pode se desenvolver em qualquer área do corpo, tendo maior incidência nas áreas expostas à radiação solar, além das mucosas, globo ocular e leptomeninge. A incidência de melanoma maligno na população brasileira é baixa: para o ano de 2012 são esperados 3.170 novos casos em homens e 3.060 em mulheres. Apesar da baixa prevalência, o melanoma tem uma elevada letalidade devido ao seu alto poder metastático. Ocorre em igual proporção entre homens e mulheres, acometendo principalmente indivíduos caucasianos. Embora apresente maior incidência na população adulta 
entre os 40 e 60 anos, o melanoma cutâneo tem sido observado em todos os grupos etários, sendo bastante rara sua manifestação na idade infantil $(1,4-6)$.

A etiologia do melanoma cutâneo permanece obscura, alguns autores têm sugerido que a gênese desta neoplasia está associada a fatores genéticos e ambientais $(5,6)$. Estudos sugerem ainda que a radiação ultravioleta proveniente dos raios solares seja o principal fator ambiental, uma vez que esses raios estimulam o potencial mitótico dos melanócitos. Não só a incidência, como também a morbidade e mortalidade do melanoma vêm aumentando em todo o mundo. O diagnóstico em fase tardia está diretamente ligado ao elevado número de sítios metatásticos, o que concerne para um mau prognóstico $(4,7,8)$.

O arsenal terapêutico para o tratamento do melanoma é composto pela associação de diferentes modalidades terapêuticas, como a quimioterapia, imunoterapia, radioterapia e cirurgia. A escolha pela melhor intervenção está diretamente ligada ao estadiamento em que se encontra o melanoma no momento do diagnóstico (4).

Há mais de quatro décadas, a terapia com laser de baixa potência (TLBP) vem sendo utilizada na prática clínica por diversos profissionais das áreas da Saúde, como uma modalidade terapêutica auxiliar para o tratamento de inúmeras condições patológicas que incluem a modulação do processo inflamatório (9-11), proliferação e diferenciação celular (12-14), angiogênese (15-17), redução da dor (18-20) e aceleração do processo de cicatrização (21-23).

Os mecanismos fotobioquímicos da TLBP ainda não foram completamente esclarecidos. Estudos sugerem que os efeitos fotobiomoduladores da interação do laser com o tecido biológico estão associados ao aumento na síntese proteica e à conversão de energia fotoquímica em nível mitocondrial (24-26). 
O laser de hélio-neônio (He-Ne) com comprimento de onda de 633 nm tem sido utilizado com sucesso em vários estudos para promover a proliferação e diferenciação de diferentes linhagens celulares. Embora os estudos realizados in vitro não apresentem relação direta entre a TLBP e o desenvolvimento do processo neoplásico, esta terapia tem sido utilizada na prática oncológica de forma cautelosa, devido a sua possível capacidade de estimular a proliferação e diferenciação de células tumorais $(27,28)$. Entretanto, o uso da TLBP no tratamento da mucosite oral induzida por quimio e/ou radioterapia é estabelecido na literatura internacional e aprovada pelo FDA (Food and Drug Administration) para uso em pacientes oncológicos (29-31).

Apesar da TLBP ser uma modalidade terapêutica bastante estudada no meio científico, seus efeitos sobre o processo neoplásico ainda permanecem pouco compreendidos. Em virtude da carência de modelos e de investigações realizadas tanto in vitro como in vivo, existe a necessidade de maiores evidências científicas sobre os mecanismos exatos de ação de diferentes parâmetros da luz, a fim de se obterem efeitos clínicos desejáveis e seguros. 


\section{OBJETIVOS}

O objetivo deste estudo foi investigar os efeitos da TLBP no comportamento de células de melanoma murino B16F10 utilizando um laser de emissão vermelha ( $K=660 \mathrm{~nm})$ com diferentes densidades de energia.

\subsection{OBJETIVOS ESPECÍFICOS}

1. Investigar a influência do estado nutricional no momento da irradiação e viabilidade celular da linhagem de melanoma B16F10;

2. Verificar o comportamento de invasão e migração celular da linhagem B16F10 de melanoma murino em resposta à TLBP;

3. Investigar o papel da TLBP na expressão de fator de crescimento vascular endotelial (VEGF). 


\section{REVISÃO DA LITERATURA}

Esta revisão não pretende exaurir o assunto, de forma que delimitamos a abordagem de aspectos relacionados ao melanoma, angiogênese e fator de crescimento endotelial vascular (VEGF), metástase bem como uma revisão sobre os efeitos da biomodulação laser em oncologia para a melhor compreensão deste estudo.

\subsection{MELANOMA}

O melanoma é um tumor maligno que se desenvolve a partir da transformação maligna dos melanócitos, células derivadas da crista neural durante o desenvolvimento embrionário, que residem na camada basal da epiderme responsáveis pela produção do pigmento melanina. Embora o sítio anatômico de maior incidência seja a pele, o melanoma pode se desenvolver em superfícies de mucosa ou em outros locais em que as células tiveram origem da crista neural $(3-5,7,32)$.

Os mecanismos exatos do processo de transformação maligna do melanoma ainda não foram totalmente esclarecido, segundo COTRAN et al (3) alterações moleculares são responsáveis por desencadear este processo induzindo o crescimento celular por meio da via proliferativa. A figura 1 mostra de maneira simplificada os mecanismos moleculares envolvidos no processo de desenvolvimento do câncer. 


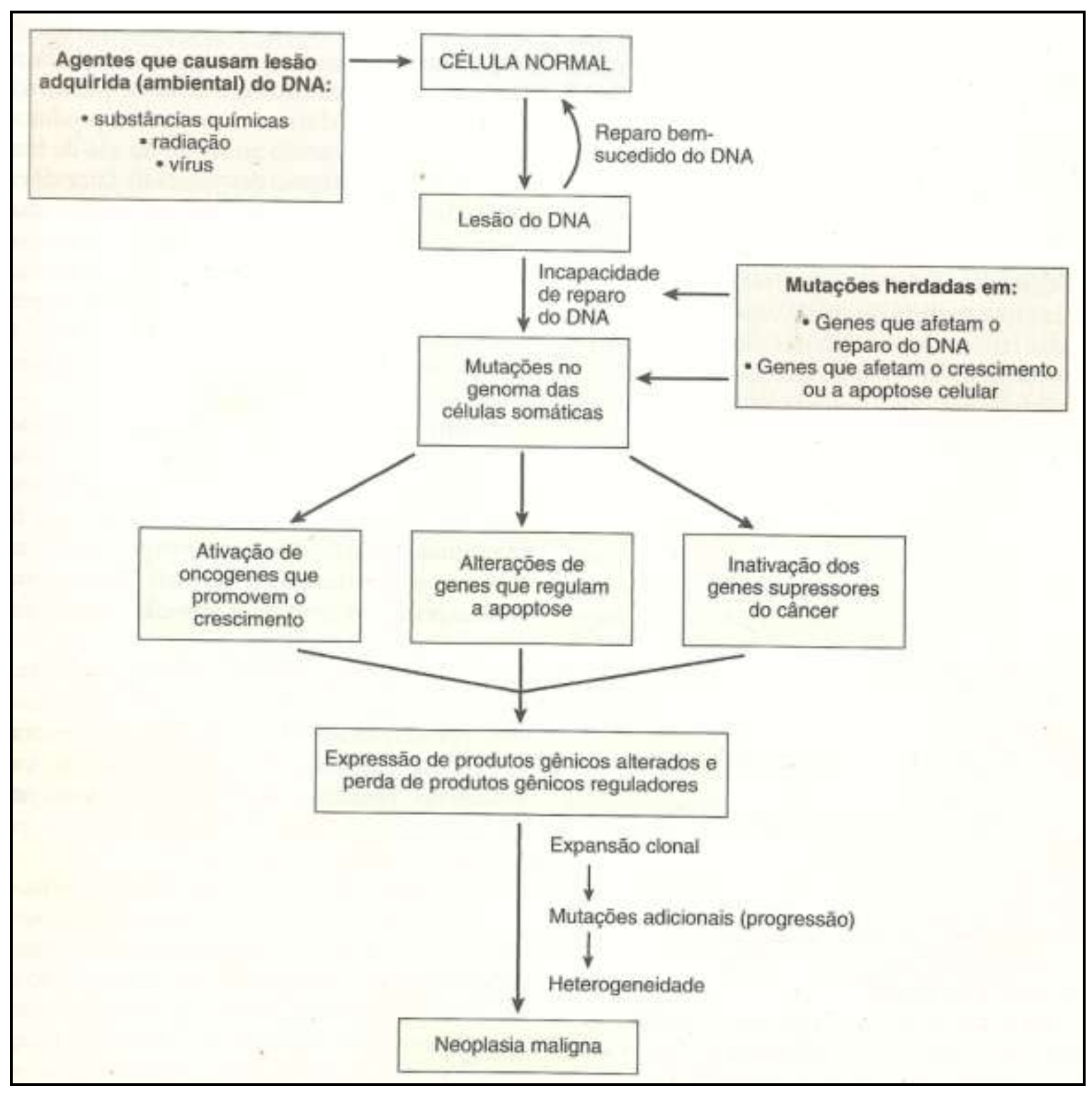

Figura 1 - Fluxograma mostrando um esquma simplificado da base molecular do câncer(3).

A ocorrência de melanoma é registrada com cuidado e a incidência é conhecida na maioria dos países. Embora as taxas de cura sejam altas é importante lembrar que ainda ocorrem mortes, apesar da ampla conscientização pública sobre a importância do diagnóstico precoce. A figura 2 mostra a estimativa do número de casos novos de câncer para o ano de 2012 em todo o Brasil. 


\begin{tabular}{|c|c|c|c|c|c|c|c|}
\hline Localização primária & casos novos & percentual & & & Localização primária & casos novos & percentual \\
\hline Próstata & 60.180 & $30,8 \%$ & Homens & Mulheres & Mama Feminina & 52.680 & $27,9 \%$ \\
\hline Traqueia, Brônquio e Pulmăo & 17.210 & $8,8 \%$ & & & Colo do Útero & 17.540 & $9,3 \%$ \\
\hline Cólon e Reto & 14.180 & $7,3 \%$ & & & Cólon e Reto & 15.960 & $8,4 \%$ \\
\hline Estômago & 12.670 & $6,5 \%$ & & & Glândula Tireoide & 10.590 & $5,6 \%$ \\
\hline Cavidade Oral & 9.990 & $5,1 \%$ & & & Traqueia, Brônquio e Pulmão & 10.110 & $5,3 \%$ \\
\hline Esôfago & 7.770 & $4,0 \%$ & & & Estômago & 7.420 & $3,9 \%$ \\
\hline Bexiga & 6.210 & $3,2 \%$ & & & Ovário & 6.190 & $3,3 \%$ \\
\hline Laringe & 6.110 & $3,1 \%$ & & & Corpo do Útero & 4.520 & $2,4 \%$ \\
\hline Linfoma nåo Hodgkin & 5.190 & $2,7 \%$ & & & Linfoma não Hodgkin & 4.450 & $2,4 \%$ \\
\hline Sistema Nervoso Central & 4.820 & $2,5 \%$ & & & Sistema Nervoso Central & 4.450 & $2,4 \%$ \\
\hline
\end{tabular}

Figura 2 - Estimativas do número de casos novos de câncer para o ano de 2012 (1).

O melanoma é raro na população negra, na qual o subtipo mais comum é a acral-letiginosa que ocorre nas extremidades, em áreas não expostas à radiação ultra-violeta, como palma das mãos, planta dos pés e região subungueal. É uma lesão agressiva, de crescimento insidioso pela dificuldade de visualização $(33,34)$.

O diagnóstico de melanoma deve ser considerado quando ocorrer qualquer mudança em uma lesão pigmentada da pele. Recentemente, o uso da microscopia de superfície cutânea foi estabelecido como ferramenta para aperfeiçoar o diagnóstico de lesões pigmentadas. Essa técnica emprega o uso de luz com lentes de aumento permitindo melhor reconhecimento dos padrões de pigmentação (4).

$\mathrm{Na}$ fase inicial quando o melanoma se desenvolve como uma proliferação intradérmica de melanócitos neoplásicos que se restringe à epiderme é dito "in situ", e nesta fase é quase sempre curável com uma excisão cirúrgica adequada $(32,35)$.

Em um estágio mais avançado pode ocorrer a formação de nódulos expansivos e infiltração da derme. Nesta fase, denominada fase de crescimento 
vertical, o melanoma adquire a capacidade de formar metástases e o prognóstico esta diretamente relacionado com a profundidade da invasão. $\mathrm{O}$ estádio em que o melanoma é diagnosticado é o fator mais importante e que influencia todo o tratamento $(32,36)$.

O melanoma primário deve ser tratado com cirurgia excisional completa com margens de segurança. A biópsia incisional deve ser reservada para as lesões grandes nas quais a excisão completa não esta indicada como manobra inicial ao diagnóstico. A margem mínima para a terapia definitiva de um melanoma invasivo é de $1 \mathrm{~cm}$ para tumores $\leq 2 \mathrm{~mm}$ e $2 \mathrm{~cm}$ para tumores maiores de $2 \mathrm{~mm}$. A profundidade da excisão deve ao menos ser igual à margem de excisão, preservando a fáscia profunda $(4,35)$.

Os melanomas subungueais são removidos com amputação, em geral a articulação mais próxima. A evidência clínica de envolvimento do linfonodo sentinela deve ser confirmada por meio de citologia por aspiração com agulha fina, confirmado o envolvimento do linfonodo esta indicada a ressecção cirúrgica de toda a cadeia ganglionar $(4,35)$.

A radioterapia no melanoma tem sido considerada em indivíduos com melanoma em região de difícil ressecção como na face próximos aos olhos, sendo sua principal indicação para o tratamento da doença metastática, onde ocorrem respostas significativas $(4,37)$.

Em pacientes com melanoma metastático a quimioterapia com agentes regulares como a dacarbazina e cisplatina apresenta uma taxa de resposta baixa. O acréscimo de interferons e interleucina-2 á quimioterapia combinada ou simplesmente imunoterapia parece resultar em taxas de respostas parciais 
maiores ou completas, entretanto, é significativamente mais tóxica e agressiva (38).

\subsection{ANGIOGÊNESE}

A angiogênese é por definição a formação de novos vasos sanguíneos e em condições fisiológicas normais é um evento essencial para a nutição dos tecidos. A neovascularização é um processo complexo com diferentes estágios: o remodelamento da matriz extracelular, migração e proliferação de células endoteliais até a formação de capilares e anastomoses. O mecanismo de angiogênese pode ser desencadeado por vários fatores: fator de crescimento fibroblástico, o fator de crescimento derivado de plaquetas, fator de necrose tumoral, óxido nítrico, e entre eles se destaca o fator de crescimento endotelial vascular (39-41).

Estudos anteriores têm mostrado a capacidade da LTBP em estimular a angiogeneses durante o processo de reparação tecidual(15,42,43). Em 2006, TUBY et al (44). demonstraram um aumento na expressão de VEGF e óxido nítrico em ratos pós infarto do miocárdio irradiados com laser de diodo (GaAs) com comprimento de onda de $804 \mathrm{~nm}$. Esses autores observaram ainda um aumento significativo na densidade de vasos sanguíneos sete dias após o infarto do miocárdio nos amimais nos quais foi utilizada uma irradiância de 5 e $12 \mathrm{~mW} / \mathrm{cm}^{2}$.

Recentemente FENG et al (45) propuseram que a expressão de VEGF em células endoteliais provenientes do cordão umbilical humano (HUVEC) após a irradiação laser de He-Ne seria regulada pela via ERK/SP. 
Com o objetivo de fornecer oxigênio e nutrientes para as células os tumores podem estabelecer o seu próprio fornecimento de sangue induzido por neovascularização e este processo é muito semelhante a angiogêneses fisiológica. A angiogêneses induzida pelas células tumorais (figura 3) apresenta características morfológicas anormais como elevada permeabilidade pela presenças de poros e a ausência de membrana basal, favorecendo assim a disseminação hematogênica.

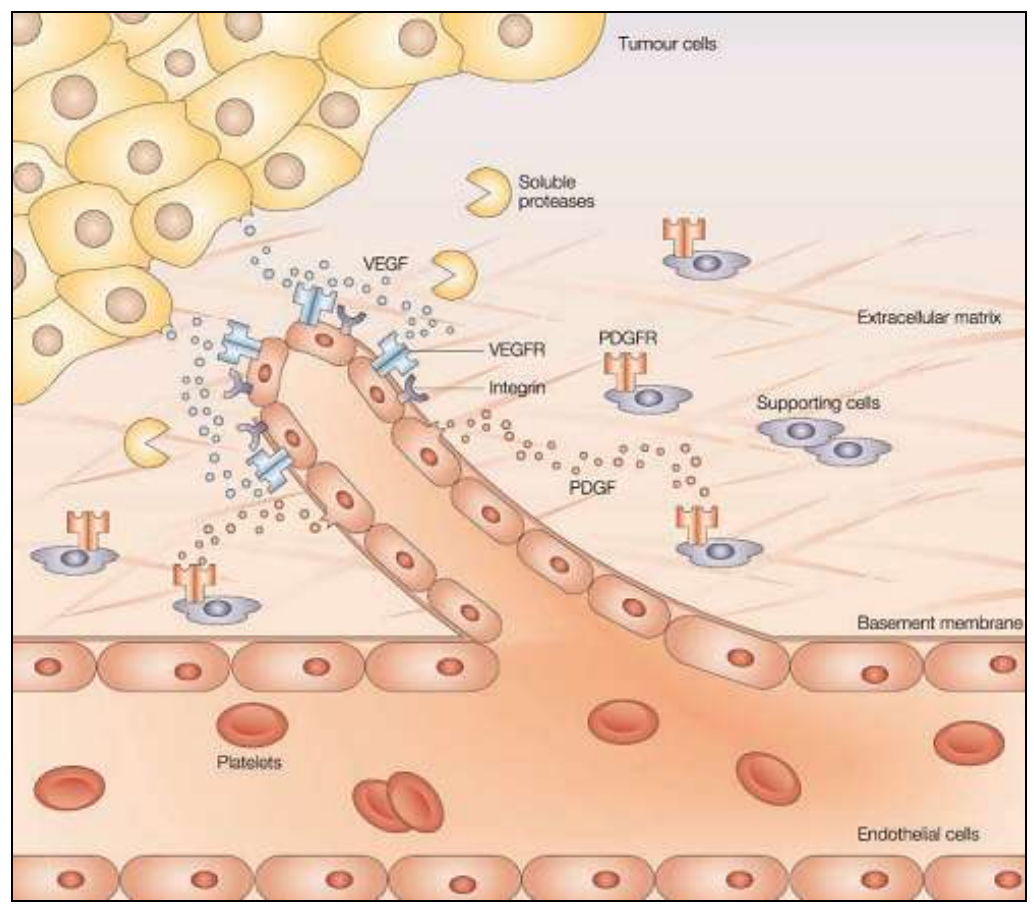

Figura 3 - llustração do processo de angiogêneses induzido por células tumorais(46)

\subsection{FATOR DE CRESCIMENTO ENDOTELIAL VASCULAR (VEGF)}

Os fatores de crescimento endotelial vascular (VEGF) é uma família de peptídeos de aproximadamente $40 \mathrm{kDa}$ e atualmente existem sete formas 
conhecidas: VEGF-A, VEGF-B, VEGF-C, VEGF-D, VEGF-E, VEGF-F e o fator de crescimento placentário (PIGF). Em condições fisiológicas normais a angiogêneses é controlada por fatores pró e anti-angiogênicos. As células neoplásicas produzem uma série de fatores que estimulam a proliferação e migração de células endoteliais, resultando na formação de novos vasos sanguíneos. Estudos sugerem que a sinalização do receptor de VEGF seja o principal fator de indução de angiogênes $(39,40,47)$.

Em 2006, VIHINEN et al(48) demonstraram uma associação entre os níveis séricos de VEGF-C com a presença de sítios metastáticos em pacientes com melanoma maligno. Esses autores sugerem que o níveis séricos de VEGF-C podem ser associados com o desenvolvimento de metástases subcutânea em doentes com melanoma e que a medição do VEGF-C também pode ter valor clínico como prognóstico para avaliar o efeito de terapias anti-angiogênicas em pacientes com melanoma metastático.

\subsection{METÁSTASE}

A capacidade de invasão e metástase são características biológicas dos tumores malignos sendo o principal fator de morbidade e mortalidade relacionadas ao câncer em todo o mundo. Os mecanismos de invasão e metástases vem sendo intensamente estudados como o objetivo de desenvolver terapias alvo mais eficazes $(4,36)$.

O melanoma apresenta um alto poder metastático e suas características invasivas aparecem na fase de crescimento vertical, quando as células penetram 
na membrana basal e crescem como um nódulo de expansão intradérmica. $A$ disseminação do melanoma ocorre a partir da dissociação de células tumorais da lesão primária, essas células migram através do estroma circundante e, ao penetrarem nos vasos sanguíneos e capilares linfáticos, podem formar um tumor em um síto distante (Figura 4). Os processos de invasão e migração do melanoma estão relacionadas com alterações na adesão celular, cuja função é controlar a organização do tecido e migração celular. Entretanto distúrbios na adesão celular contribuem para a invasão de células tumorais favorecendo a formação de metastases à distância.

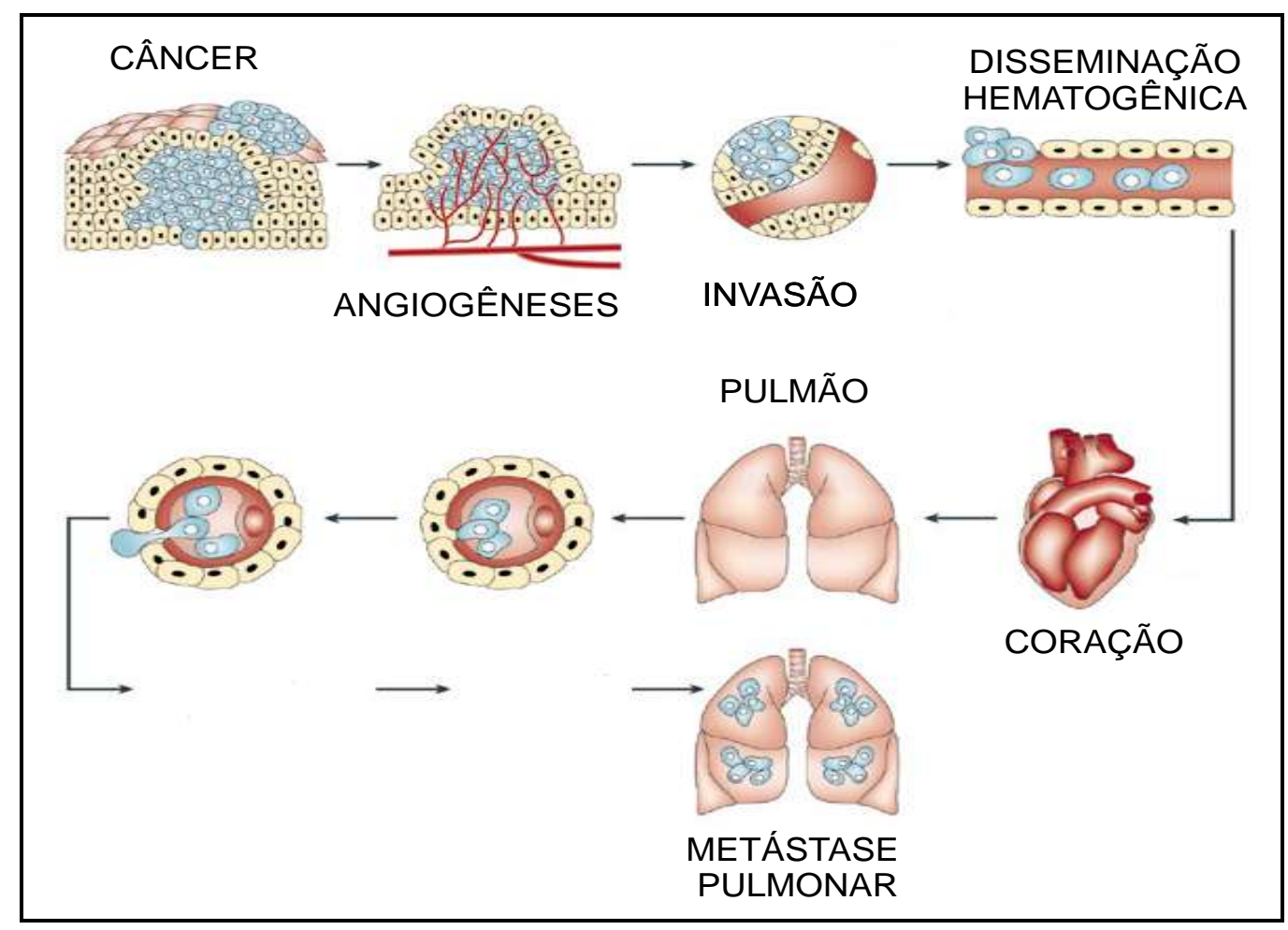

Figura 4 - llustração do processo de invasão, angiogêneses, disseminação hematogênica e a formação de sítios metastáticos (modificado de .FIDLER) (49) 


\subsection{FOTOBIOMODULAÇÃO}

A terapia com uso de luz de baixa potência tem seu início no final da década de 60 juntamente com o surgimento do primeiro dispositivo LASER desenvolvido pelo pesquisador Theodore Harold Maiman. Desde então, diversos tipos de fontes luminosas foram desenvolvidas, com diferentes materiais e com emissão em diferentes comprimentos de onda no espectro eletromagnético para as mais variadas finalidades (50).

Os lasers de baixa potência tem sido utilizados na área biomédica desde o seu desenvolvimento devido a sua capacidade de interagir com os tecidos biológicos desencadeando respostas terapêuticas.

A energia proveniente de um fóton pode ser utilizada na medicina para promover o aquecimento de estruturas, é o caso da terapia laser de alta potência, ou ser absorvido por estruturas específicas sem causar aumento significativo da temperatura local desencadeando respostas biológicas por meio do efeito fotoquímico e/ou fotofísico $(24,26,51,52)$.

Segundo KARU (24), os efeitos da TLBP em nível celular são resultantes da absorção do fóton por um fotoreceptor que após absorver a energia da irradiação assume um estado eletricamente excitado desencadeando um efeito biológico mensurável representado pelo aumento da síntese de DNA e RNA, pela modulação da resposta imune, pela produção de NO, entre outros. Segundo a mesma autora, a efetividade do tratamento com laser de baixa potência depende do estado fisiológico e nutricional em que o tecido se encontra no momento da 
irradiação, ou seja, em tecidos saudáveis a TLBP parece não desecadear nenhuma resposta biológica.

Segundo VLADIMIROV et al (25); KARU(51) e WILDEN e KARTHEIN(26) a irradiação com laser de emissão no espectro visível atua na cadeia redox da mitocôndria enquanto que a ação fotofísica do laser infravermelho é mais pronunciada na membrana celular. Nos dois casos, acredita-se que há o desencadeamento de uma resposta celular gerando uma cascata de reações bioquímicas e alterações de processos biológicos com conotação terapêutica. Ainda de acordo com esses autores, diante de uma dose de energia muito baixa pode ocorrer pouco ou nenhum efeito biomodulatório, ao passo que altas doses podem levar à inibição do efeito ou ao dano do tecido, entretanto faz-se necessário o conhecimento específico da patologia e do tecido a ser tratado para que se selecione a dosagem correta e efetiva para aplicação da TLBP.

Nas últimas décadas tem sido observado um crescente interesse no entendimento do mecanismo de interação da LTBP com o processo tumoral.(12,53-62) O crescente interesse é justificado pela capacidade da LTBP em estimular a proliferação celular e angiogêneses relatada em inúmeros estudos.

$\mathrm{Na}$ literatura são poucos os estudos que tiveram como objetivo principal estudar os efeitos da TLBP sobre o comportamento de células tumorais. Embora sejam poucos, os tipos de linhagens celulares são os mais diversos, bem como os parâmetros de irradiação e as técnicas de avaliação.

Diante da escassez de evidências científicas sobre os efeitos da TLBP no processo neoplásico bem como sobre a sua segurança em pacientes com 
neoplasia malignas seu uso na prática oncológica tem sido restrito ao tratamento da mocusite oral associada à quimioterapia e/ou radioterapia.

Recentemente a TLBP tem sido empregada no tratamento de linfedema em mulheres submetidas a mastectomia com esvaziamento ganglionar axilar KAVANI et al (63); OMAR et al (64); CARATI et al (65). Esses autores incluíram nos grupos irradiados apenas mulheres com câncer de mama que haviam sido submetidas ao tratamento cirúrgico curativo. Foram excluídas do protocolo de estudo as mulheres com relato de metástases. Esses autores concluem que a TLBP com comprimento de onda de $904 \mathrm{~nm}$ pode ser uma ferramenta adjuvante para o tratamento de linfedema após mastectomia com esvaziamento axilar.

Os efeitos biomodulativos da irradiação com laser díodo de $805 \mathrm{~nm}$ em células tumorais de carcinoma gengival humano (ZMK), em carcinoma urotelial (J82), em culturas de células musculares (C2) e uroteliais (HCV29) normais foram estudados por SCHAFFER et al (61), usando as técnicas de coloração de orceína para determinar o índice mitótico e a coloração BrdU para determinar a proliferação celular. Esses autores observaram crescimento significativo até a fluência de $4 \mathrm{~J} / \mathrm{cm}^{2}$ apresentando redução do padrão de crescimento após esta dose. Nesse mesmo estudo a linhagem de carcinoma gengival humano (ZMK) apresentou redução do índice mitótico, que permaneceu o mesmo em doses maiores de $4 \mathrm{~J} / \mathrm{cm}^{2}$.

OÇAÑA-QUERO et al (57), estudaram os efeitos biológicos da irradiação laser He-Ne em linhagem celular de mieloma (Sp2-Ag14) de camundongo, observaram um aumento de células nas fases $G_{0}-G_{1}$ e uma diminuição significativa de células nas fases $S$ do ciclo celular nos grupos irradiados com 
densidade de energia entre 8 e $64 \mathrm{~J} / \mathrm{cm}^{2}$ quando comparado com o grupo controle e nenhuma diferença foi observada nas fases $\mathrm{G}_{2}-\mathrm{M}$ do ciclo celular.

Os efeitos da TLBP na proliferação celular ainda permanecem um tópico controverso na literatura, pois a associação de diferentes tipos celulares, parâmetros de irradiação e estado nutricional desencadeiam ora efeito estimulante levando o crescimento celular, ora como agente inibidor.

Em 2005, foi demonstrado por WERNECK et al (62) a capacidade da LTBP na proliferação de células de carcinoma de laringe (HEp2) irradiadas com diferentes comprimentos de onda $685 \mathrm{~nm}$ e $830 \mathrm{~nm}$, a proliferação celular foi avaliada pelo ensaio de metabolização de MTT. Eles observaram um aumento na proliferação celular $12 \mathrm{~h}$ após a irradiação no grupo irradiado com $685 \mathrm{~nm}$, enquanto que no grupo irradiado com comprimento de onda de $805 \mathrm{~nm}$ esse crescimento foi observado após às $48 \mathrm{~h}$. Os autores sugerem que clinicalmente a irradiação de uma lesão maligna poderia resultar no crescimento tumoral.

Segundo RENNO et al (60) embora as evidências acumuladas até o momento excluam a radiação laser de baixa potência como um agente carcinógeno, na literatura há indícios suficientes para sugerir que esta modalidade terapêutica pode ter um efeito fotobioestimulador positivo em linhagem de células tumorais. Estes autores analisaram o efeito de três diferentes comprimentos de onda na proliferação e diferenciação celular em linhagens de osteoblasto e osteosarcoma. Concluíram que cada linhagem celular responde diferentemente para uma combinação específica de comprimento de onda e dose de energia.

POWEL et al (59) estudaram os efeitos da irradiação laser com comprimento de $780 \mathrm{~nm}, 830 \mathrm{~nm}$ e $904 \mathrm{~nm}$ na proliferação de células de carcinoma de mama humano, melanoma e célula epitelial imortalizada. A dose 
utilizada variou ente 0,5 e $15 \mathrm{~J} / \mathrm{cm}^{2}$ Esse autores sugerem prudência na utilização da TLBP no tratamento de lifedema secundário à cirurgia e /ou radioterapia em mulheres com câncer de mama. 


\section{MATERIAIS E MÉTODOS}

\subsection{CULTIVO CELULAR}

A linhagem celular B16F10 utilizada neste estudo foi gentilmente cedida pela Dra. Maria Lucia Zaidan Dagli do Departamento de Medicina Veterinária e Zoologia da Universidade de São Paulo. A amostra foi estocada e congelada em nitrogênio líquido. Um tubo criogênico contendo a amostra foi descongelado rapidamente em banho-maria a $37^{\circ} \mathrm{C}$. Antes de ser manipulado em câmera de fluxo laminar, o tubo criogênico foi limpo com álcool etílico 70\% e o seu conteúdo removido para um tubo cônico, com $10 \mathrm{~mL}$ de meio de cultura RPMl fresco e centrifugado por 5 minutos a $300 \mathrm{~g}$ em temperatura ambiente para remover a substância crioprotetora (di-metil-sulfóxido-DMSO). O sobrenadante foi desprezado e as células precipitadas foram ressuspensas em $1 \mathrm{~mL}$ de meio de cultura fresco. O meio de cultura utilizado foi o meio RPMI 1640 (Vitrocell Embriolife, Campinas, São Paulo, Brazil) suplementado com 10\% de soro fetal bovino (Cultilab, São Paulo, Brasil) e 1\% de solução antibiótico-antimicótica (Sigma). Neste momento as células foram semeadas em frasco de cultura previamente preparado. O frasco de cultura foi observado ao microscópio invertido e posteriormente mantido em estufa a $37^{\circ} \mathrm{C}$ e $5 \%$ de $\mathrm{CO}_{2}$ com a tampa entreaberta até alcançar a confluência (Figuras 5 e 6). 


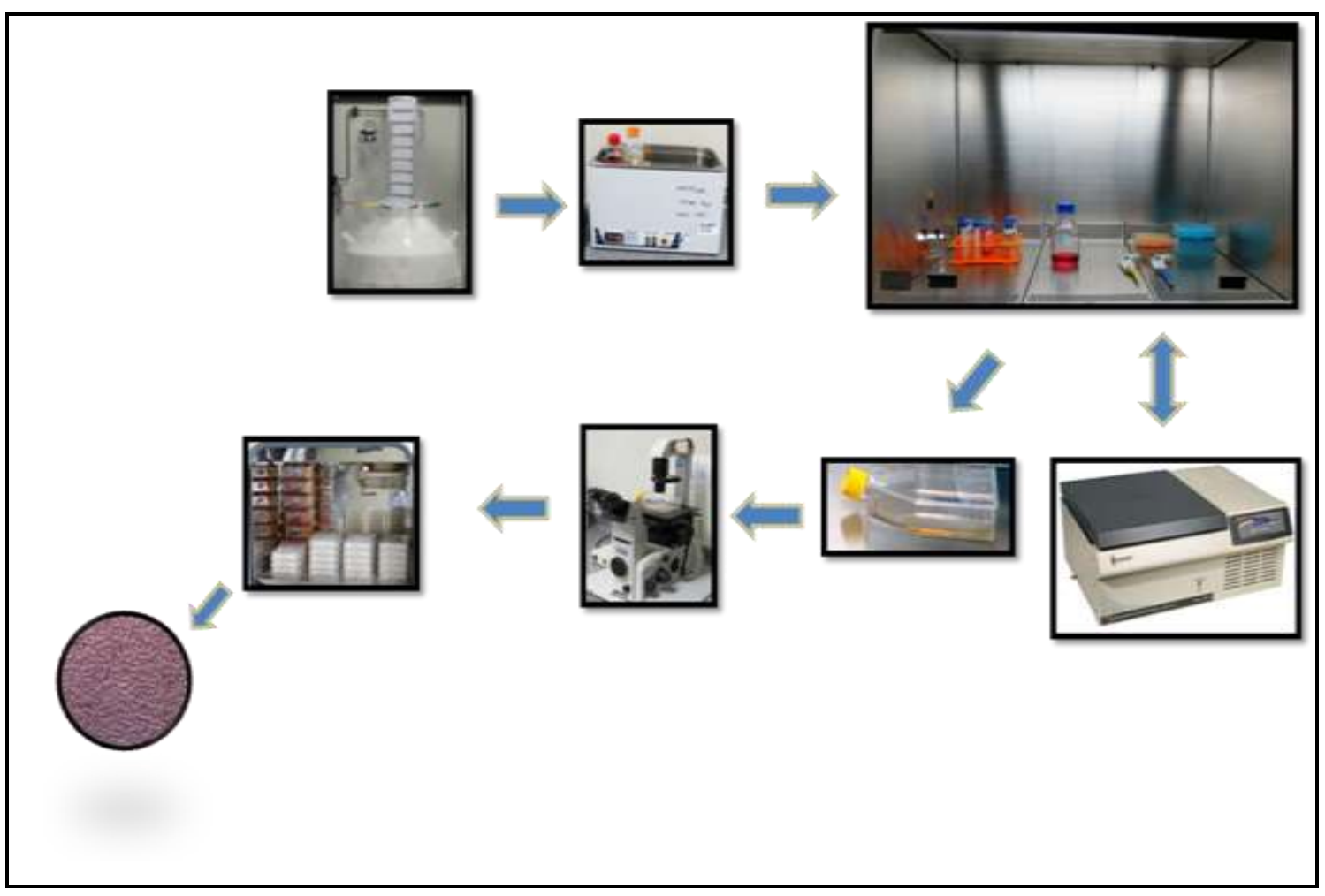

Figura 5 - Sequência do processo de descongelamento e expansão da linhagem celular B16F10 de melanoma murino.

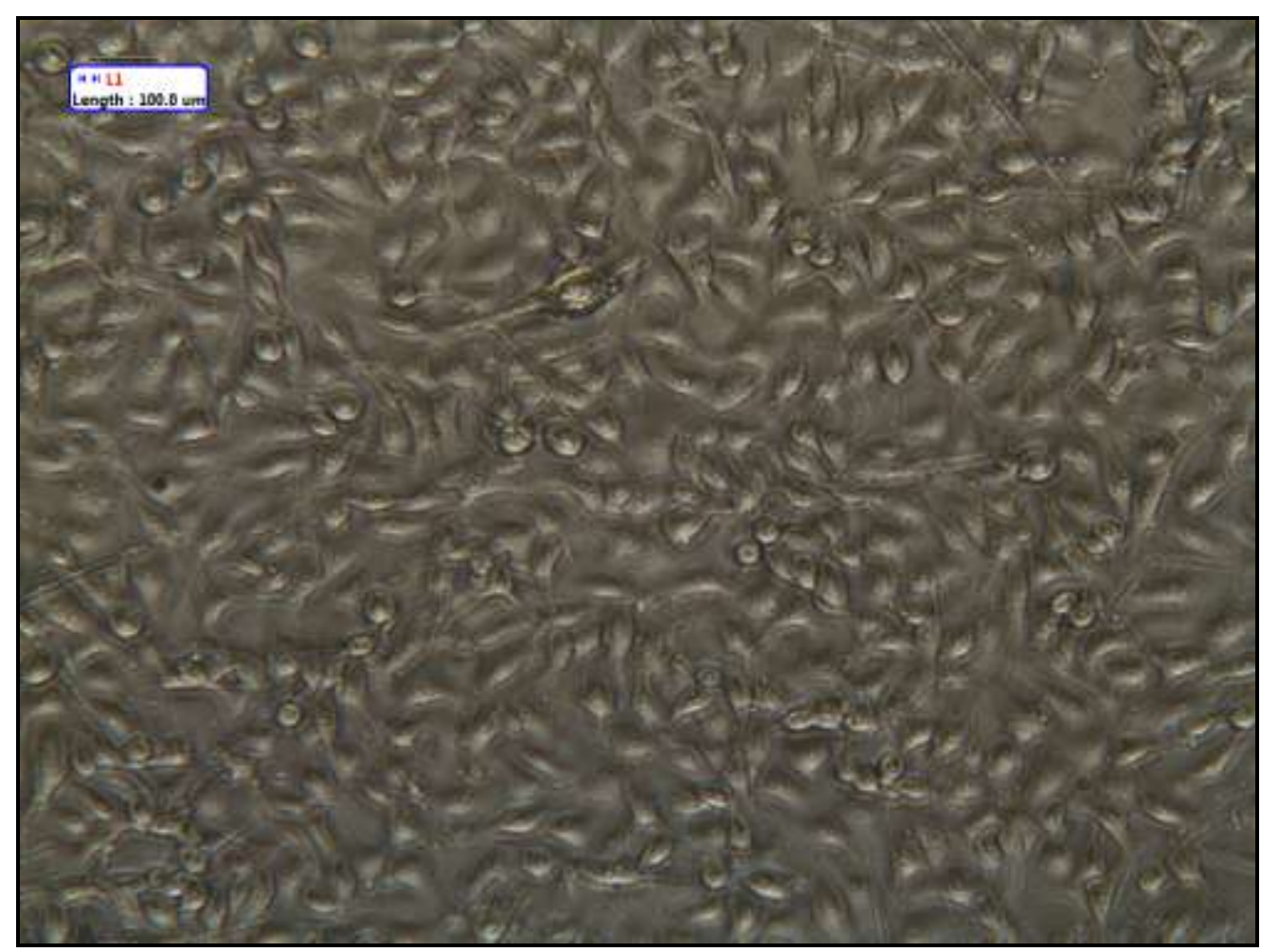

Figura 6 - Linhagem celular de melanoma B16F10 vista em microscópio invertido. 
Para o subcultivo celular, o meio foi removido do frasco e a monocamada celular aderida lavada duas vezes com uma solução salina tamponada com fosfato (PBS) sem cálcio e sem magnésio, $(\mathrm{pH} 7,2)$. A seguir, para desprender as células, foram adicionados $3 \mathrm{~mL}$ de solução de tripsina $0,25 \%$ durante $5 \mathrm{~min}$ a $37^{\circ} \mathrm{C}$. A tripsina foi neutralizada com $5 \mathrm{~mL}$ de meio de cultura fresco contendo soro fetal bovino e as células em suspensão transferidas para um tubo de ensaio e centrifugadas a $300 \mathrm{~g}$ durante 5 min à temperatura ambiente. O sobrenadante foi removido e o precipitado de células foi ressuspendido em $1 \mathrm{~mL}$ de meio de cultura fresco. Para a perpetuação da linhagem celular, frações dessa suspensão de células foram subcultivadas em novos frascos, procedimento que visa a manutenção da cultura. Para que a viabilidade das células fosse preservada, a troca do meio de cultura dos frascos foi realizada a cada três dias. Alíquotas dessa cultura foram congeladas em nitrogênio líquido para manter estoque da linhagem (Figura 7). 


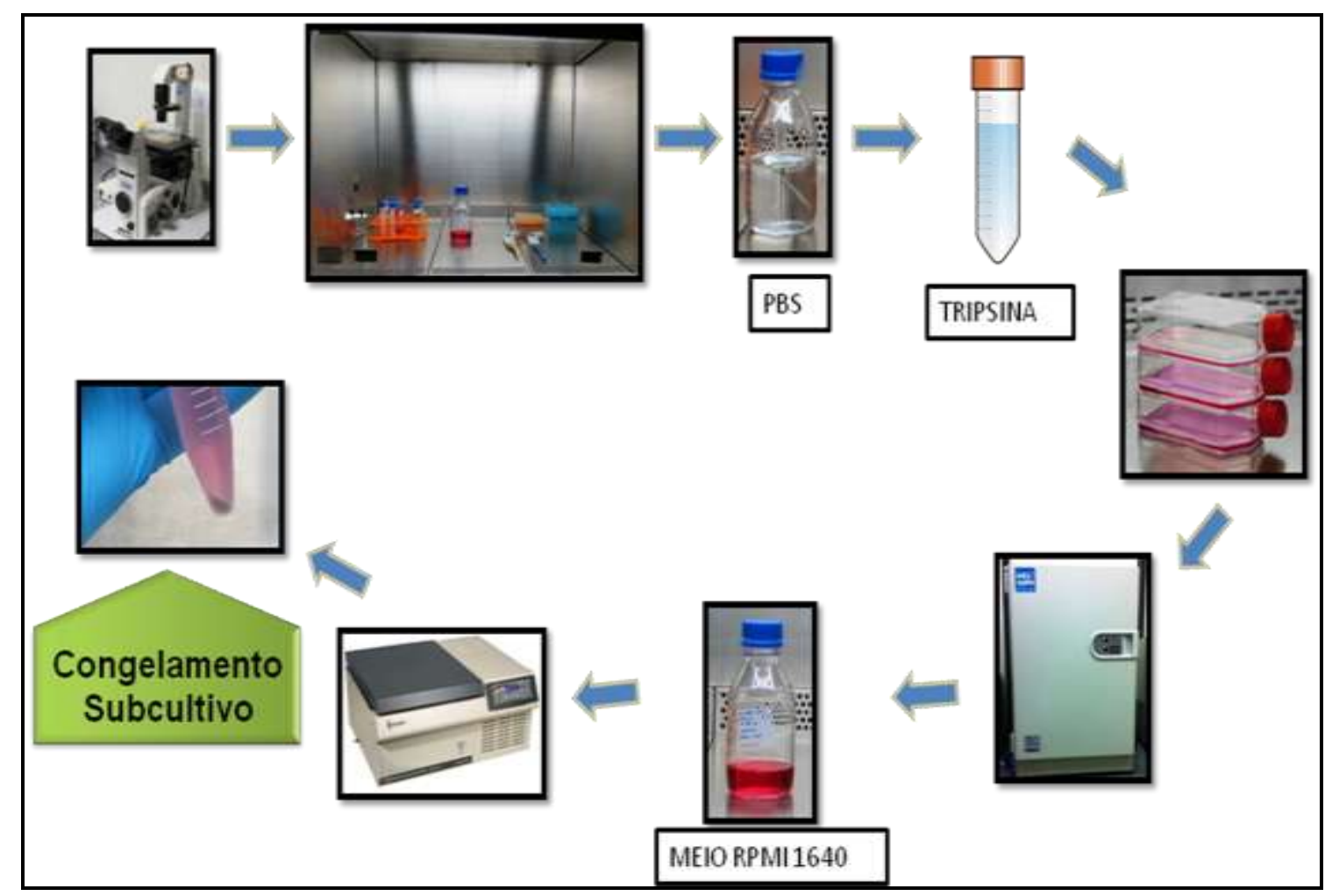

Figura 7 - Sequência do processo de repique e subcultivo da linhagem celular B16F10 de melanoma murino.

\subsection{VIABILIDADE CELULAR}

Para a obtenção do número de células do experimento, foi realizada a contagem de células viáveis através do uso do hemocitômetro (Câmara de Neubauer) e o método de exclusão de células coradas pelo azul de Trypan. Seguiu-se o mesmo protocolo do subcultivo celular, e o precipitado ressuspendido em $1 \mathrm{~mL}$ de PBS sem cálcio e sem magnésio. Parte desta suspensão de células $(100 \mu \mathrm{L})$ foram removidos para um tubo tipo eppendorf, onde foram adicionados $800 \mu \mathrm{L}$ de PBS sem cálcio e sem magnésio e $100 \mu \mathrm{L}$ de azul de Trypan. Em seguida, cada uma das duas câmaras do hemocitômetro recebeu $15 \mu \mathrm{L}$ dessa nova suspensão e as células foram contadas em microscópio invertido (Figura 8). 
O número total de células foi obtido através da seguinte equação matemática: número total de células contadas $\mathrm{x}$ diluição $\times 10^{4} /$ número de quadrados do hemocitômetro usados para a contagem.

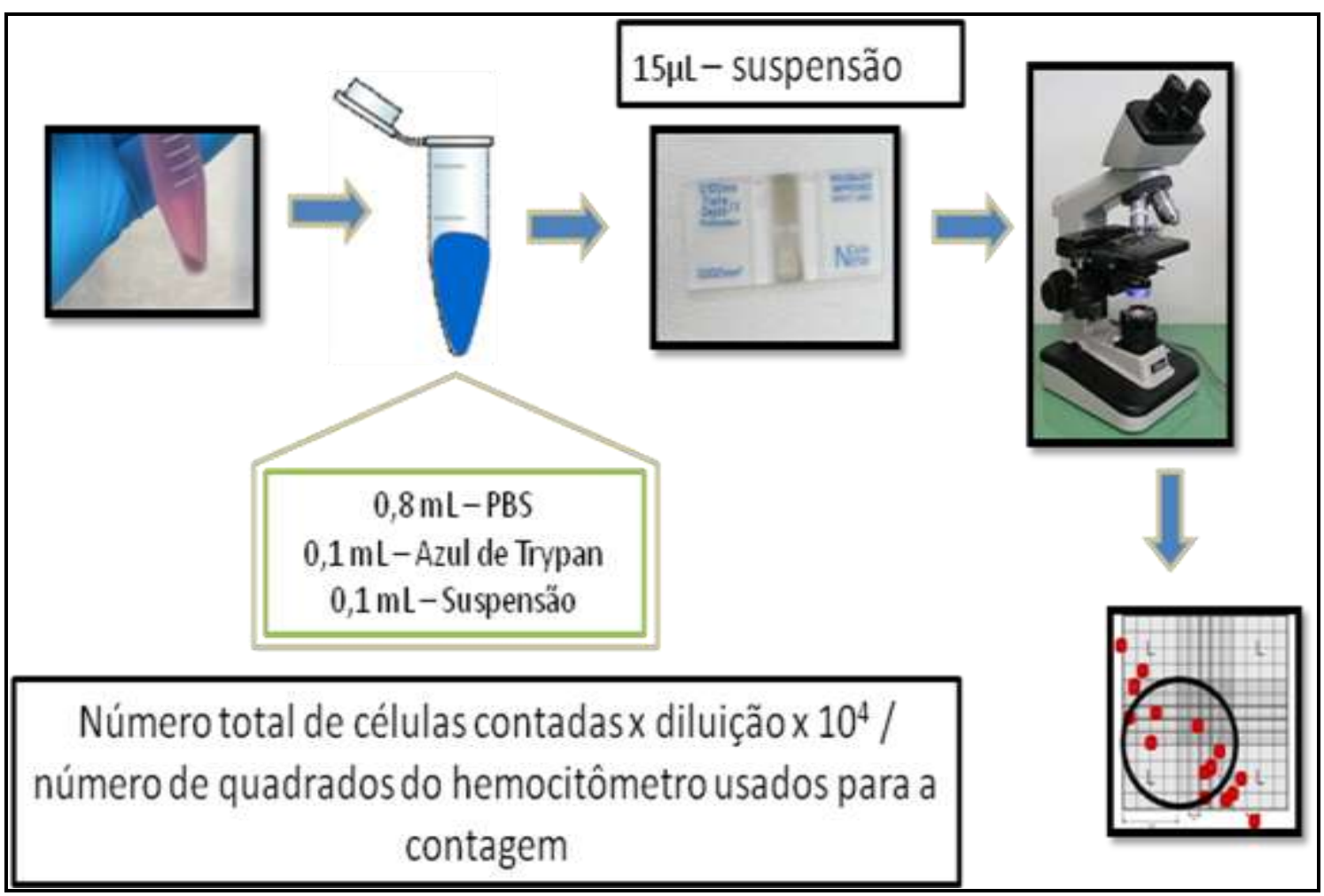

Figura 8 - Sequência do processo de contagem de células viáveis da linhagem celular B16F10 de melanoma murino.

Somente as células mortas aparecem coradas em azul, pela penetração do azul de Trypan devido às lesões na membrana celular. A exclusão destas células da contagem geral serviu para a determinação da viabilidade celular.

Para os experimentos de viabilidade celular foram plaqueadas as mesmas quantidades de células em placas de 96 poços tipo ELISA (12 placas) divididas em 10 grupos experimentais e um grupo controle, totalizando 144 poços. A concentração celular para o plaqueamento foi de $5 \times 10^{3}$ células/poço e os 
experimentos foram realizados em quadruplicata para cada grupo. As células foram cultivadas em meio de cultura RPMI com suplemento nutricional adequado (SFB a 10\%) e em déficit nutricional com 5\% de SFB (Figura 9).

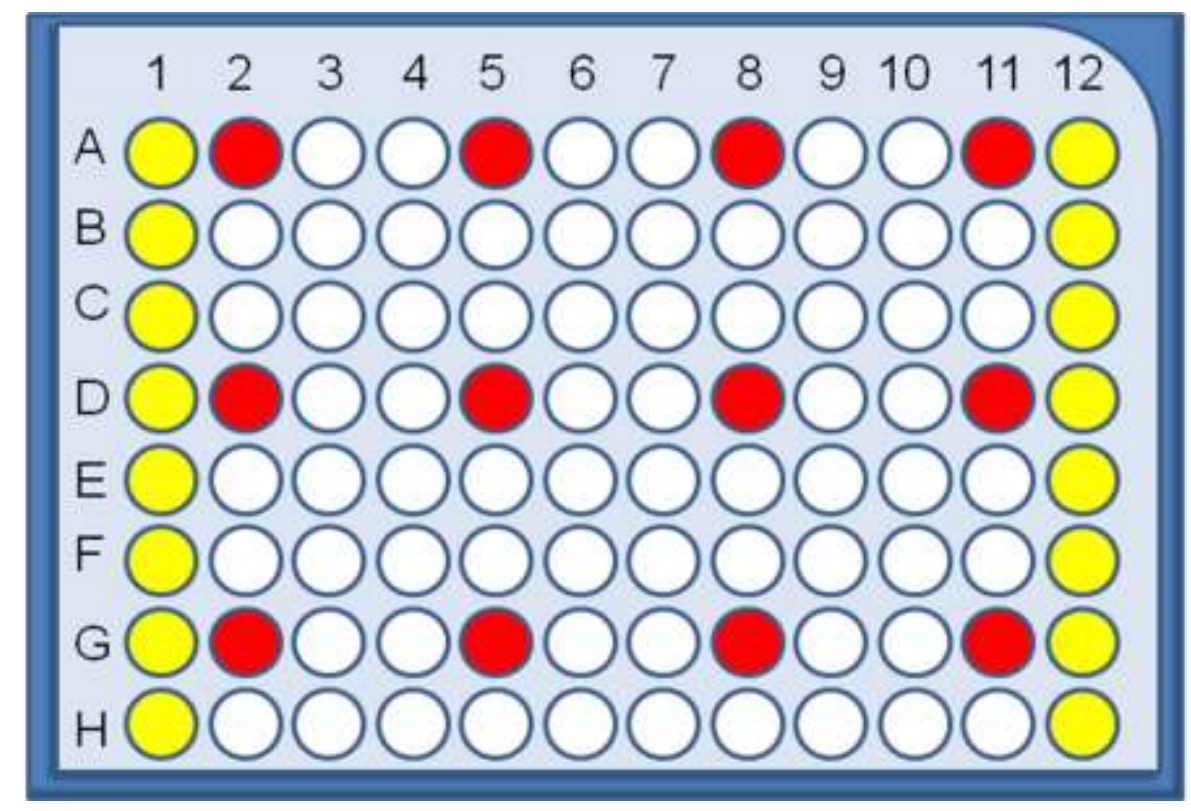

Figura 9 - Distribuição dos poços experimentais (vermelho); em amarelo, poços contendo PBS.

\subsection{EQUIPAMENTO LASER}

O equipamento laser utilizado foi o Twin Flex Evolution (MMOptics Ltda, São Carlos, SP, Brasil) classificado como laser classe 3B, emitindo no comprimento de onda do vermelho visível (InGaAIP), com comprimento de onda de $660 \mathrm{~nm}$. Os grupos experimentais foram submetidos a uma única irradiação de forma pontual com os parâmetros demonstrados na tabela 1. 
Tabela 1 - Parâmetros utilizados durante as irradiações com laser.

\begin{tabular}{|c|c|c|c|c|c|}
\hline Amostra & $\begin{array}{c}\text { Área do spot laser } \\
\left(\mathbf{c m}^{2}\right)\end{array}$ & $\begin{array}{c}\text { Tempo } \\
(\mathbf{s})\end{array}$ & $\begin{array}{c}\text { Potência de saída } \\
(\mathbf{m W})\end{array}$ & $\begin{array}{c}\text { Fluência } \\
\left(\mathbf{J} / \mathbf{c m}^{2}\right)\end{array}$ & $\begin{array}{c}\text { Energia } \\
(\mathbf{J})\end{array}$ \\
\hline Grupo 0 & - & - & - & - & \\
\hline Grupo 30 & 0,04 & 30 & 40 & 30 & 1,2 \\
\hline Grupo 60 & 0,04 & 60 & 40 & 60 & 2,4 \\
\hline Grupo 90 & 0,04 & 90 & 40 & 90 & 3,6 \\
\hline Grupo 120 & 0,04 & 120 & 40 & 120 & 4,8 \\
\hline Grupo 150 & 0,04 & 150 & 40 & 150 & 6 \\
\hline
\end{tabular}

Os experimentos foram desenhados de maneira padronizada. Para irradiação, cada placa foi acomodada previamente dentro de um dispositivo tipo máscara escura feita de papel cartolina preto fosco, recebendo luz somente nos orifícios correspondentes aos poços experimentais que estavam sendo utilizados (Figura 10).

A distância entre o feixe laser e a monocamada celular foi mantida constante, uma vez que a distância entre o feixe e a superfície de aplicação interferem na dosagem final. Neste estudo, a aplicação foi realizada posicionando-se a ponteira do equipamento em contato com a base de cada poço experimental (técnica pontual) (Figura 11). O risco de contaminação da cultura foi minimizado pelo fato da irradiação ser realizada em contato com a base da placa sem necessidade de abrir a tampa. Todas as placas foram colocadas dentro do fluxo laminar ao mesmo tempo, inclusive as placas contendo os grupos controle, onde permaneceram até que o último grupo fosse irradiado. 


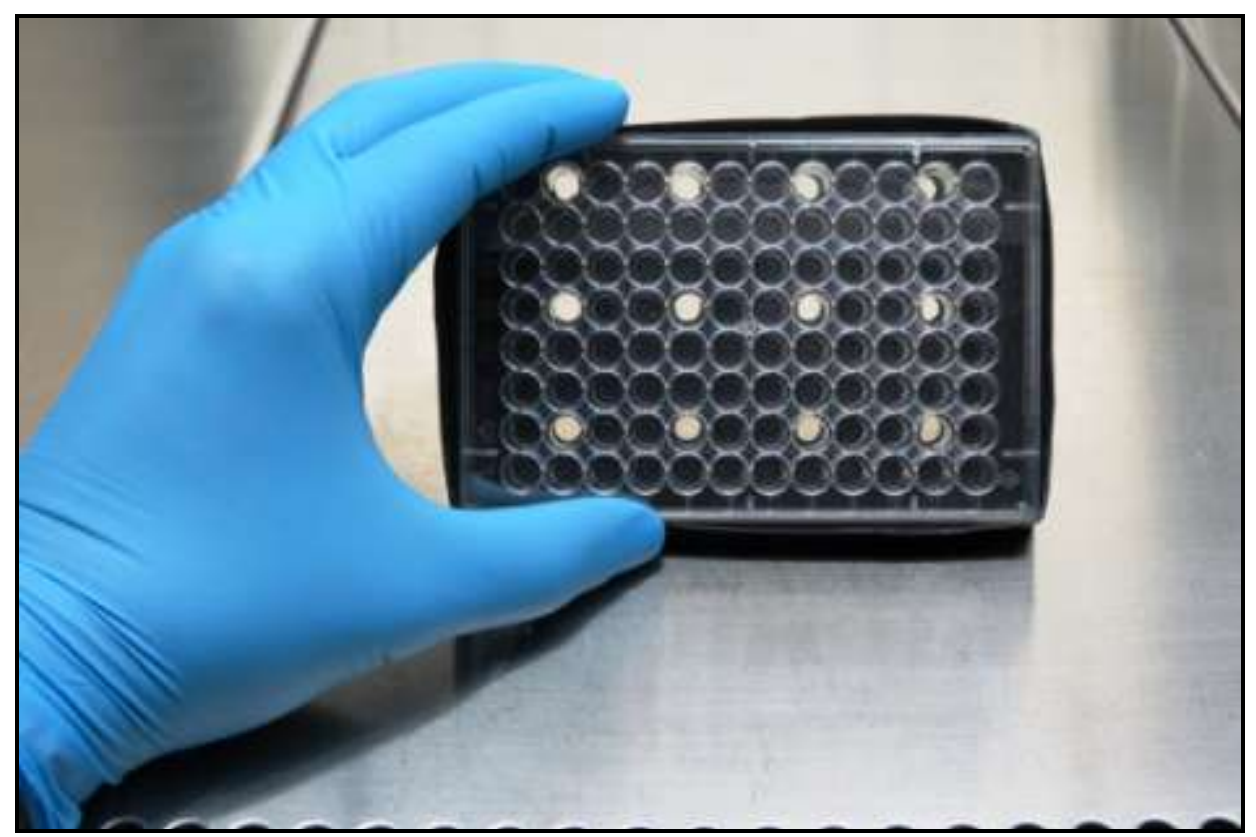

Figura 10 - Máscara escura utilizada durante o processo de irradiação.

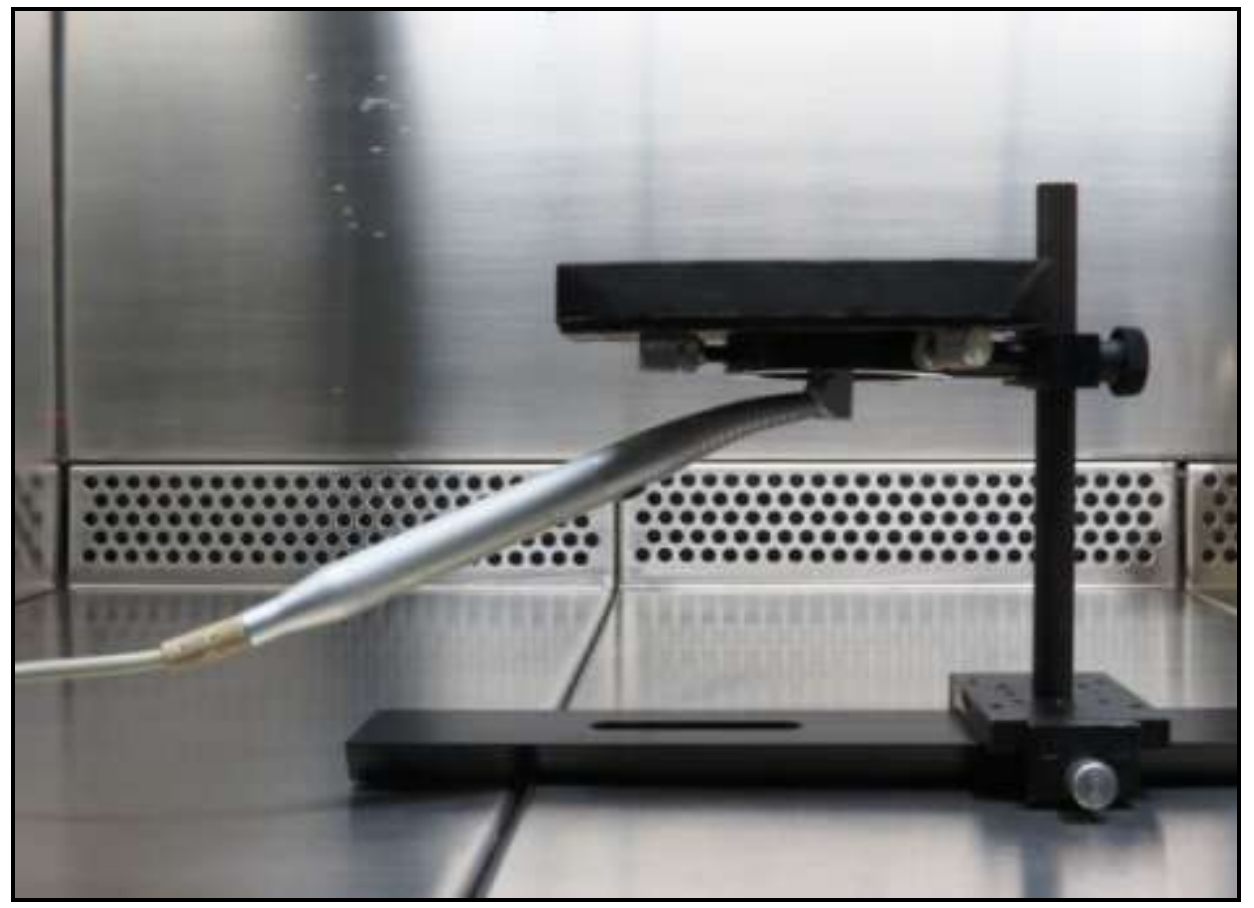

Figura 11 - Aparato utilizado para fixar a ponteira do laser em contato constante com o fundo do poço durante o tempo de irradiação. 


\subsection{CURVAS DE VIABILIDADE CELULAR}

A viabilidade celular foi realizada utilizando-se a técnica de mensuração da atividade mitocondrial por MTT (3-(4,5-dimetiltiazol-2yl)-2,5-difenil brometo de tetrazolina) (SIGMA, USA).

Após a irradiação, as placas foram levadas novamente para estufa a $37^{\circ} \mathrm{C}$ em atmosfera de $\mathrm{CO}_{2}$ a $5 \%$. A cada tempo experimental (24 h, 48 h e 72 h após a irradiação), uma placa contendo os grupos experimentais em quadruplicata, tiveram o meio de cultura aspirado. Cada poço foi lavado com $100 \mu \mathrm{L}$ de PBSA. Para análise da viabilidade celular, foi adicionado $50 \mu \mathrm{L}$ de MTT (3-(4,5dimetiltiazol-2yl)-2,5-difenil brometo detetrazolina). As placas foram incubadas em estufa a $37^{\circ} \mathrm{C}$ e atmosfera de $\mathrm{CO}_{2}$ a $5 \%$ por $3 \mathrm{~h}$ envoltas em papel alumínio. Após esse período, foi possível observar a formação de cristais que foram dissolvidos adicionando $100 \mu \mathrm{L}$ de DMSO (dimetilssulfóxido) em cada poço. Em seguida, as placas foram colocadas na leitora de ELISA para a leitura da absorbância em $450 \mathrm{~nm}$. Poços contendo o MTT, mas sem células, foram utilizados como controle negativo para a leitura (Figura 12). 


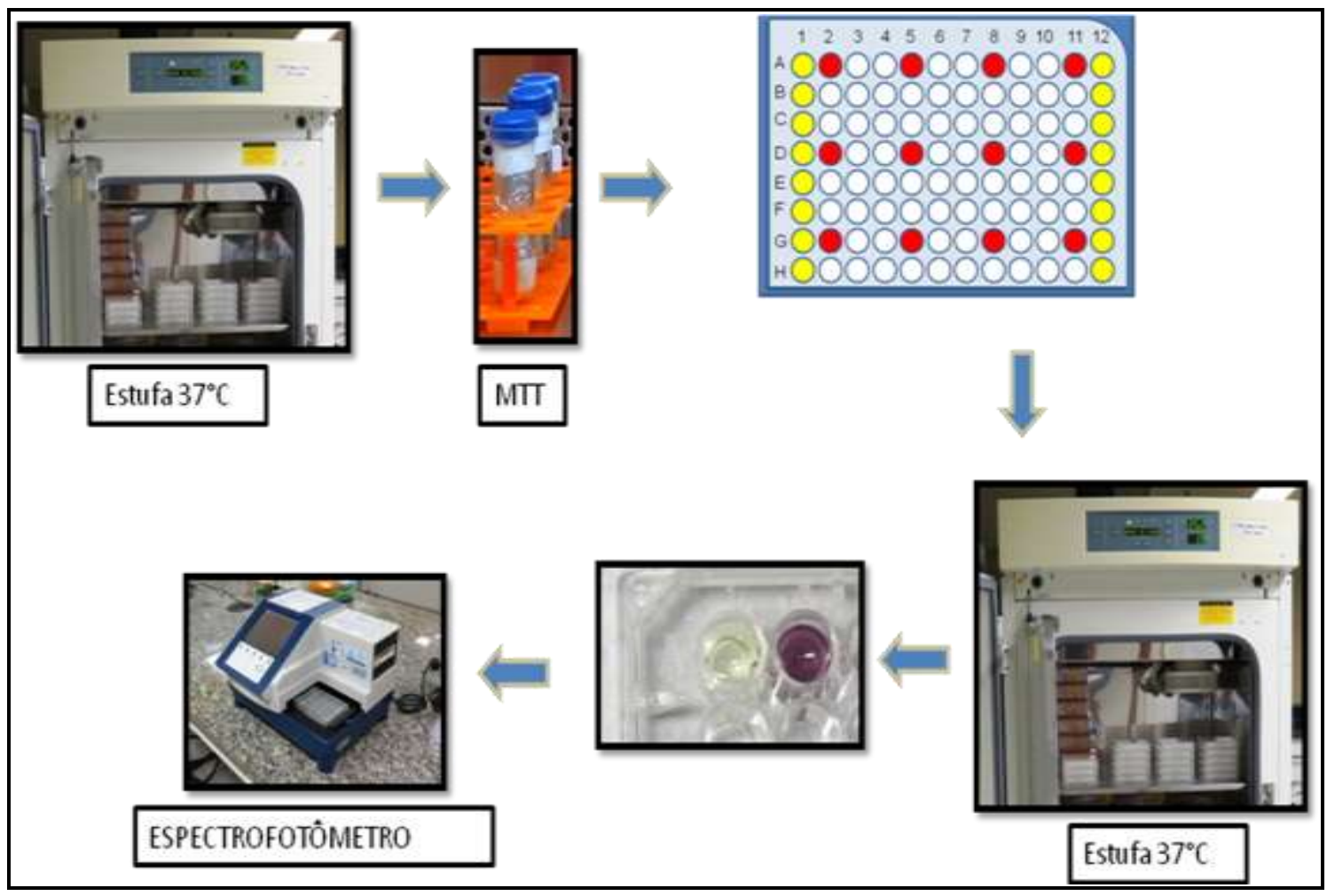

Figura 12 - Sequência experimental do ensaio de viabilidade celular por meio da técnica de MTT.

\subsection{ENSAIO DE MIGRAÇÃO TRANSWELL}

O ensaio de migração transwell é uma poderosa ferramenta para a patologia investigativa por possibilitar o estudo do comportamento de invasão e migração de diferentes tipos celulares. Esta técnica é composta por câmaras bipartites para cultura de células, são dispositivos de fácil manipulação, baixo custo e significativa acurácia pois simula in vitro a membrana basal (Figuras 13 e14). 


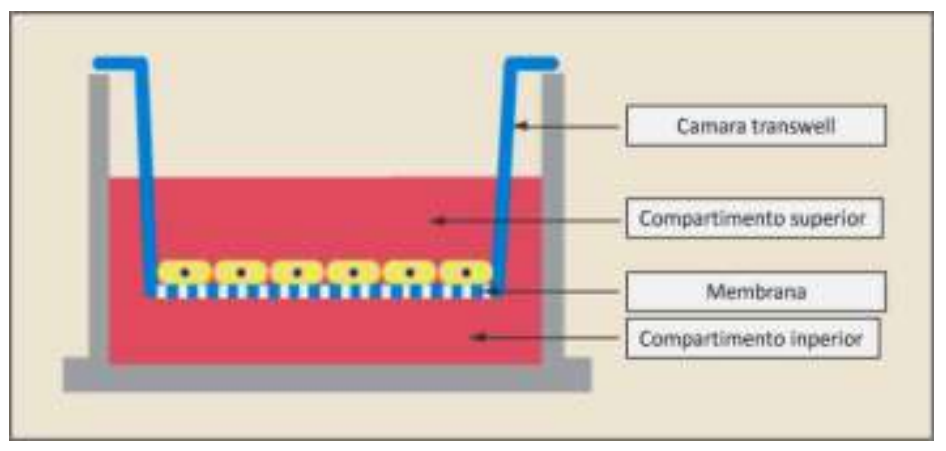

Figura 13 - Ilustra o início da técnica, sobre a membrana superior estão as células em estudo.

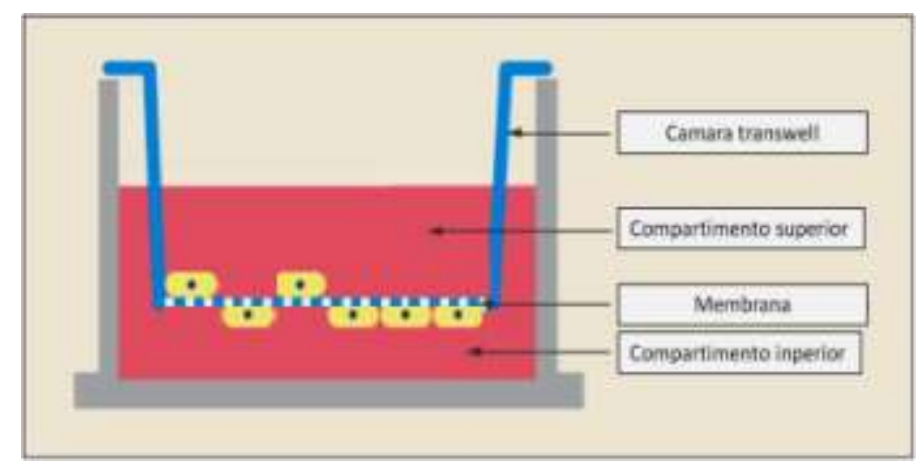

Figura 14 - llustra o final da técnica onde no compartimento inferior é possível observar as células que migraram.

Neste estudo para o ensaio de migração foram utilizandos filtros com poros de $8 \mu \mathrm{m}$ em placas de 24 poços (Corning, USA). Os filtros foram preparados com $24 \mathrm{~h}$ de antecedência, onde se adicionou ao compartimento superior $25 \mu \mathrm{L}$ de matrigel $(200 \mu \mathrm{g} / \mathrm{mL})$ em meio de cultura RPMI fresco sem soro fetal bovino. As células foram colocadas em estresse nutricional trocando o meio de cultura por meio RPMI fresco sem soro fetal bovino por $12 \mathrm{~h}$. As células foram tripsinizadas e uma suspensão contendo $1 \times 10^{6}$ células $/ \mathrm{mL}$ foi colocada no compartimento superior da câmara, enquanto no compartimento inferior foi adicionado $600 \mu \mathrm{L}$ de meio de cultura RPMI suplementado com soro fetal bovino a $10 \%$. A placa foi incubada por $6 \mathrm{~h}$ a $37^{\circ} \mathrm{C}$ em estufa de $\mathrm{CO}_{2}$ para que ocorresse 
a adesão e migração das células. Transcorrido o período de incubação o conteúdo do compartimento superior foi cuidadosamente removido (células que não migraram e meio de cultura). As células que migraram foram fixadas em metanol a $-20^{\circ} \mathrm{C}$ e em seguida coradas por hematoxilina e eosina.

Após a confecção das lâminas foram realizadas imagens adquiridas em microscópio invertido em um aumento final de 600x para a determinação do número de células que migraram. Cada experimento foi realizado em triplicata (Figura 15).

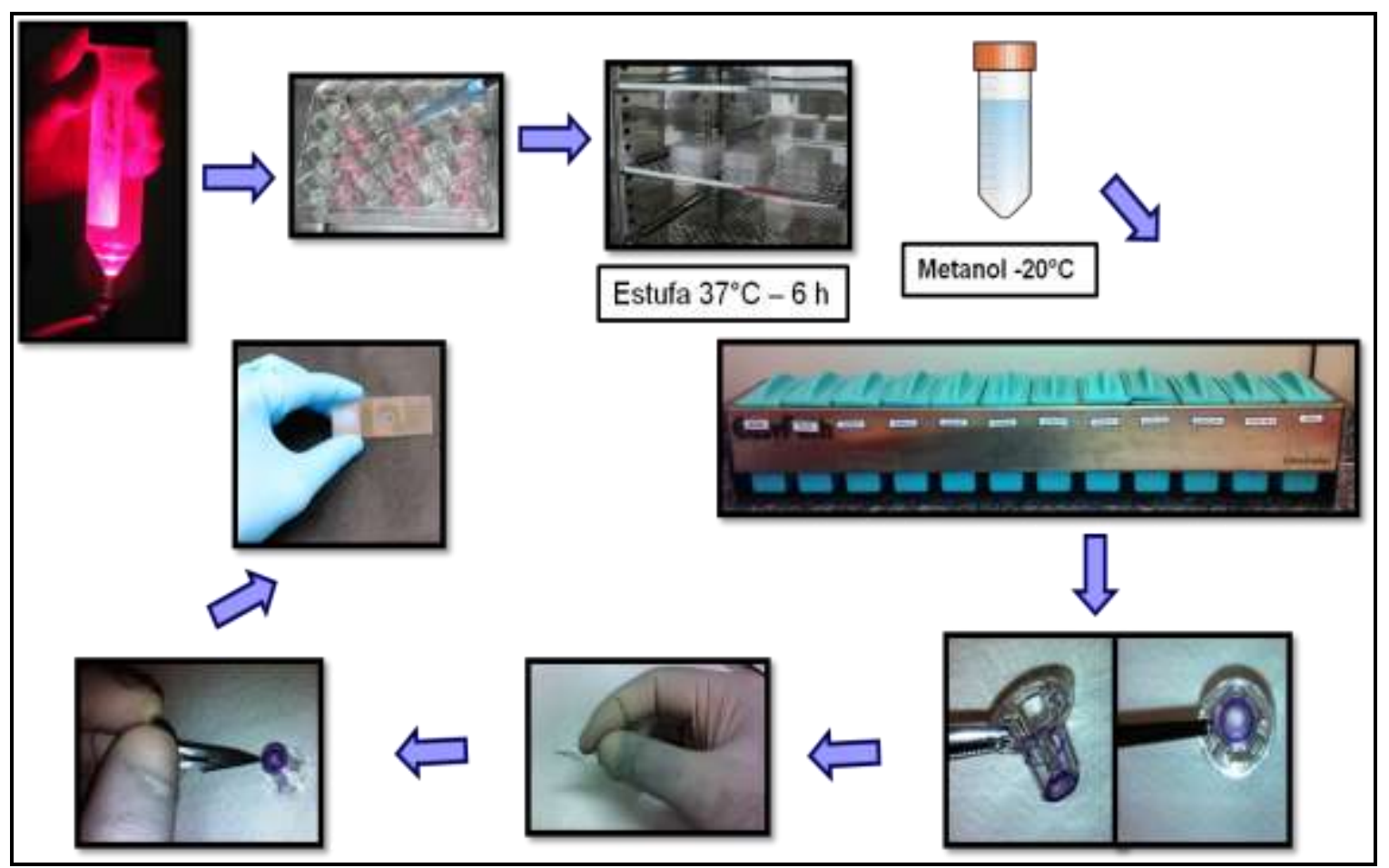

Figura 15 - Sequência experimental do ensaio de migração celular por meio da técnica de transwell.

\subsection{ENSAIO IMUNOENZIMÁTICO PARA DOSAGEM DE VEGF}

O termo ELISA é um acrômio do termo inglês Enzyme-Linked Immunosorbent Assay é um ensaio diagnóstico tanto qualitativo quanto 
quantitativo utilizado para detectar a presença de antígenos $(\mathrm{Ag})$ ou anticorpo $(\mathrm{Ac})$ específicos em fluidos corporais ou sobrenadantes de cultura celulares. Essa técnica foi inicialmente desenvolvida por ENGVALL e PERLMANN citado por LEQUIN (66), publicaram em seu primeiro artigo a medição quantitativa de IgG de soro de coelho utilizando fosfatase alcalina como marcador. Exitem vários modelos de testes de ELISA. O mais utilizado na prática clínica diagnóstica e experimental é a sua forma simples chamado de ELISA indireto, na qual um antígeno está aderido a um suporte sólido, placa de ELISA previamente preparada, sobre a qual é colocada a amostra a ser testada (soro ou sobrenadante de culturas celulares) para detecção de anticorpos contra o antígeno. Se houver a presença de anticorpos na amostra em teste ocorrerá a ligação antígeno-anticorpo, que posteriormente será detectada pela adição de um segundo anticorpo marcado com uma enzima denominada "conjugado" que reage com o substrato fazendo com que o cromógeno mude de cor. A presença de cor nos poços em estudo indica a presença de anticorpos e os poços que não mudaram de cor indica a ausência de anticorpos. A quantificação do substrato é realizada por meio de um leitor de placas por medidas de densidade óptica (DO).

Para a dosagem de VEFG (fator de crescimento endotelial vascular) neste estudo foi utilizado o teste ELISA sanduíche ou captura. Os sobrenadantes produzidos pela linhagem B16F10 de melanoma murino dos poços experimentais foram removidos nos tempos $24 \mathrm{~h}, 48 \mathrm{~h}$ e $72 \mathrm{~h}$ após a terapia laser de baixa potência e acondicionado em tubos tipo eppendorf previamente identificado. Os tubos foram levados ao freezer $-20{ }^{\circ} \mathrm{C}$ por um período de $24 \mathrm{~h}$ e mantidos em freezer a $-80^{\circ} \mathrm{C}$. Posteriormente os sobrenadantes foram usados para quantificar 
a expressão do VEGF determinado pelo ensaio imunoenzimático ELISA (Quantitative Kit-Invitrogen®) seguindo as instruções do fabricante.

As amostras foram descongeladas em temperatura ambiente e diluídas na concentração 1:4 (50 $\mu \mathrm{L}$ de sobrenadante e $150 \mu \mathrm{L}$ de diluente tampão), $100 \mu \mathrm{L}$ da amostra foram adicionados em uma placa de 96 poços revestidos com anticorpos e incubada por $1 \mathrm{~h}$ em temperatura ambiente. Em seguida a placa foi lavada quatro vezes com o tampão de lavagem fornecido pelo fabricante e secada em papel toalha. Após foi adicionado $100 \mu \mathrm{L}$ do segundo anticorpo, em seguida a placa foi incubada por $1 \mathrm{~h}$ em temperatura ambiente. Repetiu-se o processo de lavagem e a placa foi incubada por 30 min, protegida da luz com $100 \mu \mathrm{L}$ de solução de estreptavidina e a reação foi interrompida adicionado $100 \mu \mathrm{L}$ da solução de parada. A placa foi submetida a leitura em espectrofotômetro com comprimento de onda de $450 \mathrm{~nm}$ (Figura 16). Neste ensaio, as amostras de sobrenadantes da cultura celular foram separadas de acordo com a dose e os diferentes tempos $24 \mathrm{~h}, 48 \mathrm{~h}$ e $72 \mathrm{~h}$. 


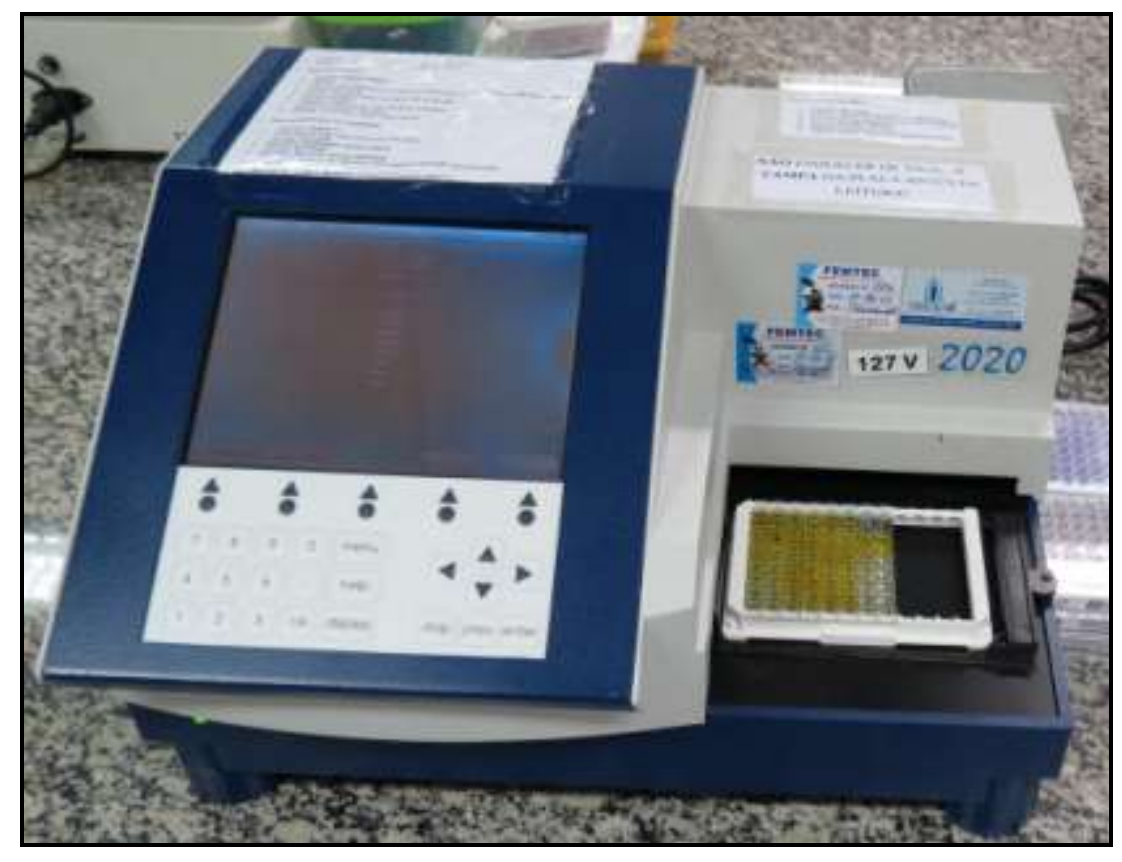

Figura 16 - Leitura do ensaio imunoenzimático (ELISA) para dosagem de VEGF em espectrofotômetro.

\subsection{ANÁLISE ESTATÍSTICA}

Os dados obtidos foram analisados estatisticamente utilizando o programa OriginPro 8. Inicialmente utilizamos o método Shapiro-Wilk que revelou uma distribuição normal dos resultados. Como a distribuição foi normal, os dados foram comparados pelo método ANOVA seguidos pelo teste de Tukey. O nível de significância adotado foi de $5 \%(P<0,05)$. 


\section{RESULTADOS E DISCUSSÃO}

$\mathrm{Na}$ literatura são encontrados estudos que utilizaram laser de baixa potência com a finalidade de avaliar seus efeitos sobre diversas linhagens celulares. Entretanto, não há consenso em relação aos diversos parâmetros envolvidos (comprimento de onda, regime de operação da fonte luminosa, potência, dose, tempo de exposição, número de irradiações e técnica de irradiação).

Na Figura 17 observa-se o comportamento celular para todos os grupos submetidos a déficit nutricional (5\% SFB). Nota-se que 48 h e 72 h após a TLBP, todos os grupos mostram maior atividade metabólica em relação ao tempo de $24 \mathrm{~h}(\mathrm{p}<0,05)$. No entanto, o padrão metabólico foi semelhante para todos os grupos, incluindo o grupo controle sem irradiação. 


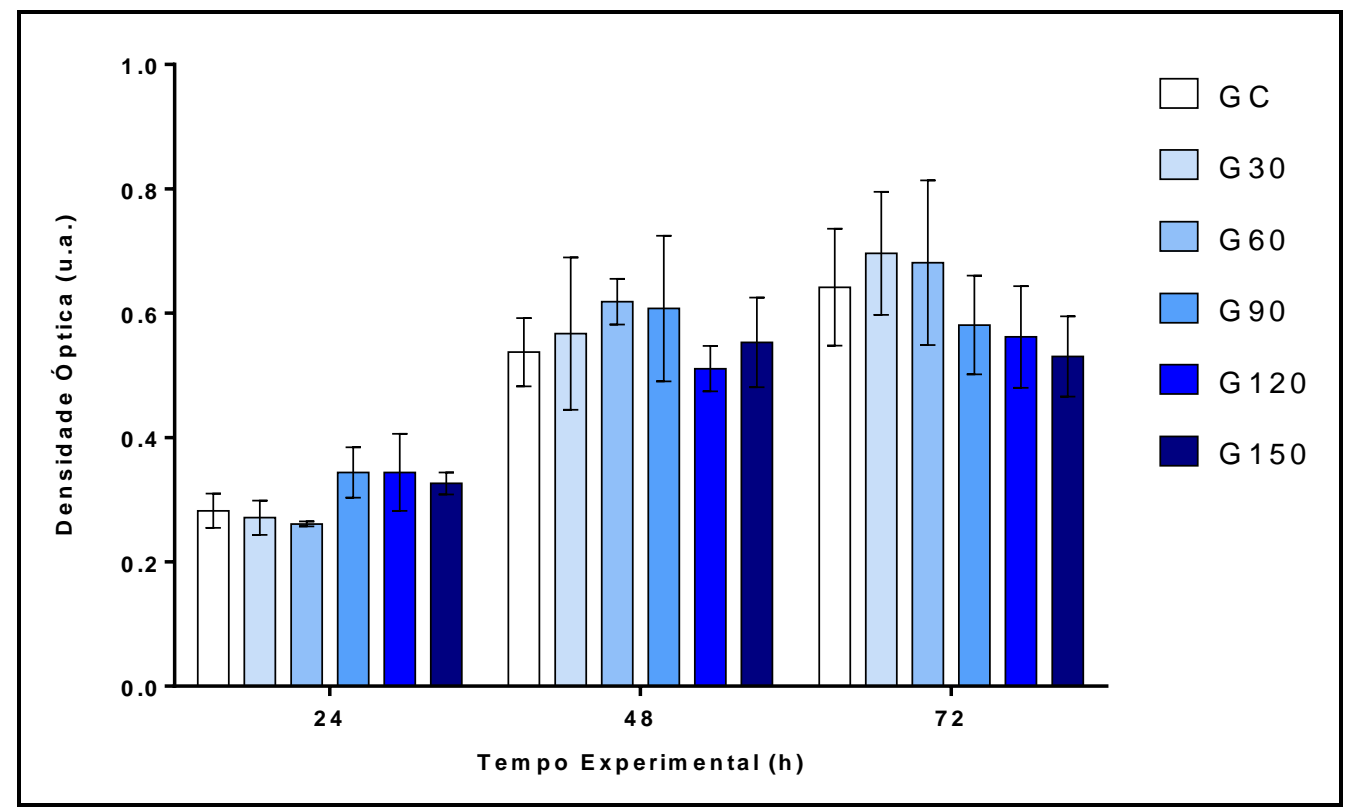

Figura 17 - Valores da média e desvio padrão correspondentes à atividade mitocondrial medida pela densidade óptica (DO) para as células de melanoma murino B16F10 cultivadas com déficit nutricional (meio RPMI suplementado com $5 \%$ SFB).

A Figura 18 apresenta o comportamento celular para todos os grupos sem déficit nutricional (10\% SFB). Como relatado anteriormente, observa-se que $48 \mathrm{~h}$ e $72 \mathrm{~h}$ após a TLBP, todos os grupos mostram maior atividade metabólica em relação ao tempo de $24 \mathrm{~h}(p<0,05)$. Entretanto, o grupo G120 não mostrou diferença estatística significativa entre os tempos 24 h e 48 h. 


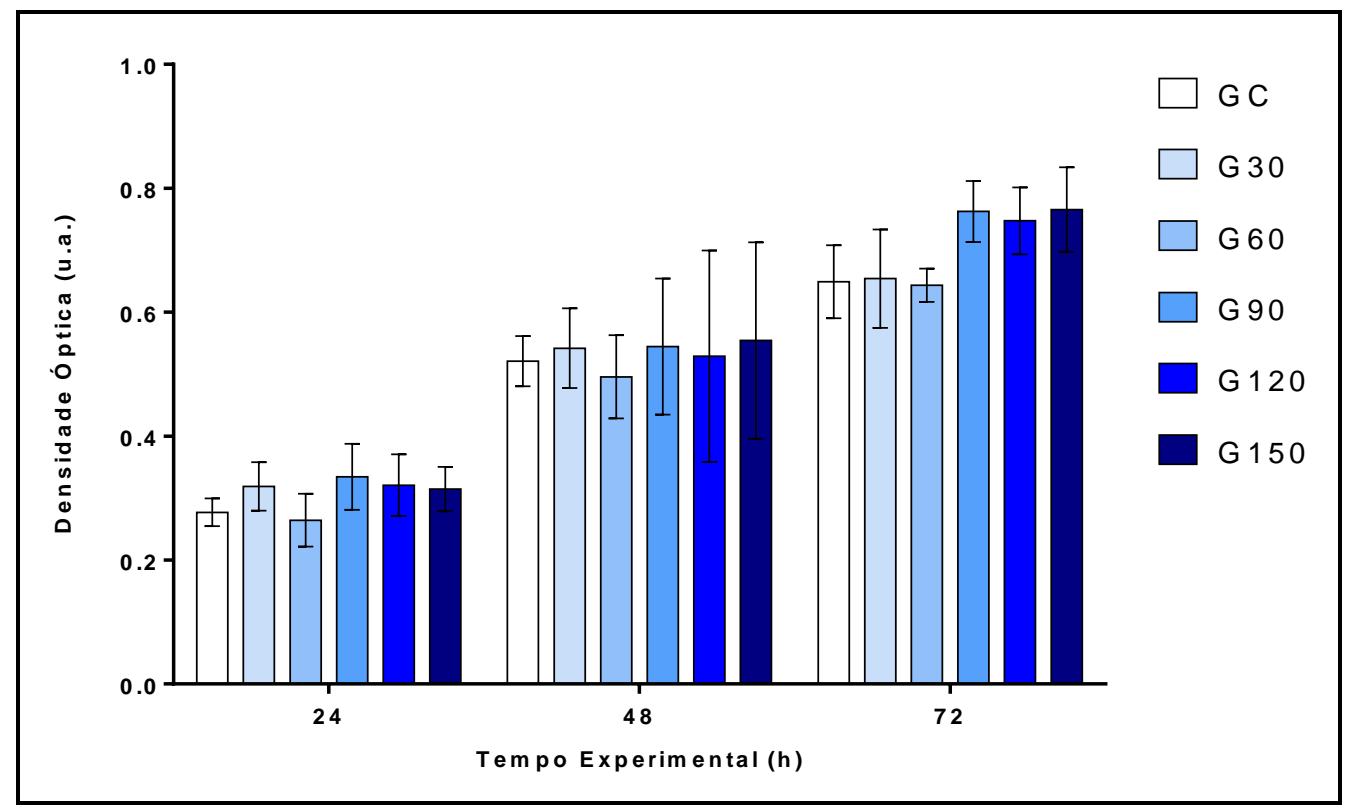

Figura 18 - Valores da média e desvio padrão correspondentes à atividade mitocondrial medida pela densidade óptica (DO) para as células de melanoma murino B16F10 cultivadas sem déficit nutricional meio RPMI suplementado com $10 \% . S F B$.

As células tumorais frequentemente se encontram com algum nível de déficit nutricional devido à sua intensa atividade metabólica, alguns autores sugerem que os efeitos fotobiomoduladores da TLBP dependem do estado fisiológico e nutricional em que a cultura se encontra antes da irradiação. Sendo assim, simulamos um microambiente com condições desfavoráveis para a cultura com a redução na concentração de soro fetal bovino (SFB). Esta metodologia tem sido utilizada para avaliação do efeito do laser de baixa potência no crescimento de fibroblastos $(67,68)$.

Em nosso estudo, as culturas celulares submetidas a déficit nutricional (5\% SFB) e as células em meio suplementado com $10 \%$ de SFB, mostraram resultados similares após $48 \mathrm{~h}$ e $72 \mathrm{~h}$, já que ambas as culturas mostraram 
aumento da atividade metabólica, sugerindo que o estado fisiológico não interfere na viabilidade celular de melanoma B16F10.

Estes achados concordam com FRIGO et al (55). Esses autores avaliaram os efeitos de TLBP com comprimento de onda de $660 \mathrm{~nm}$ em linhagem celular de melanoma B16F10 murino in vitro e in vivo, mesmo comprimento de onda e tipo de linhagem celular utilizado neste estudo. A irradiação foi realizada por três dias consecutivos e as taxas de fluências utilizadas foram de $150 \mathrm{~J} / \mathrm{cm}^{2}$ e $1050 \mathrm{~J} / \mathrm{cm}^{2}$. Esses autores relataram não ter observado efeitos na proliferação celular em culturas sem déficit nutricional.

No entanto, nossos resultados discordam de WERNECK et al (62) que avaliaram os efeitos de dois comprimentos de onda na proliferação em linhagem celular de carcinoma laríngeo humano Hep2 em défict nutricional. Esses autores mostraram que a TLBP tem efeito positivo na proliferação celular sobre a linhagem Hep2 em déficit nutricional, irradiada com os comprimentos de onda de $685 \mathrm{~nm}$ e $830 \mathrm{~nm}$ quando comparado com o controle.

É possível observar nas Figuras 19 e 20, que para os tempos de $24 \mathrm{~h}$ e 48 h, há um comportamento semelhante para as culturas com déficit e sem déficit nutricional. Com relação às densidades de energia, nenhuma diferença estatisticamente significante foi observada. 


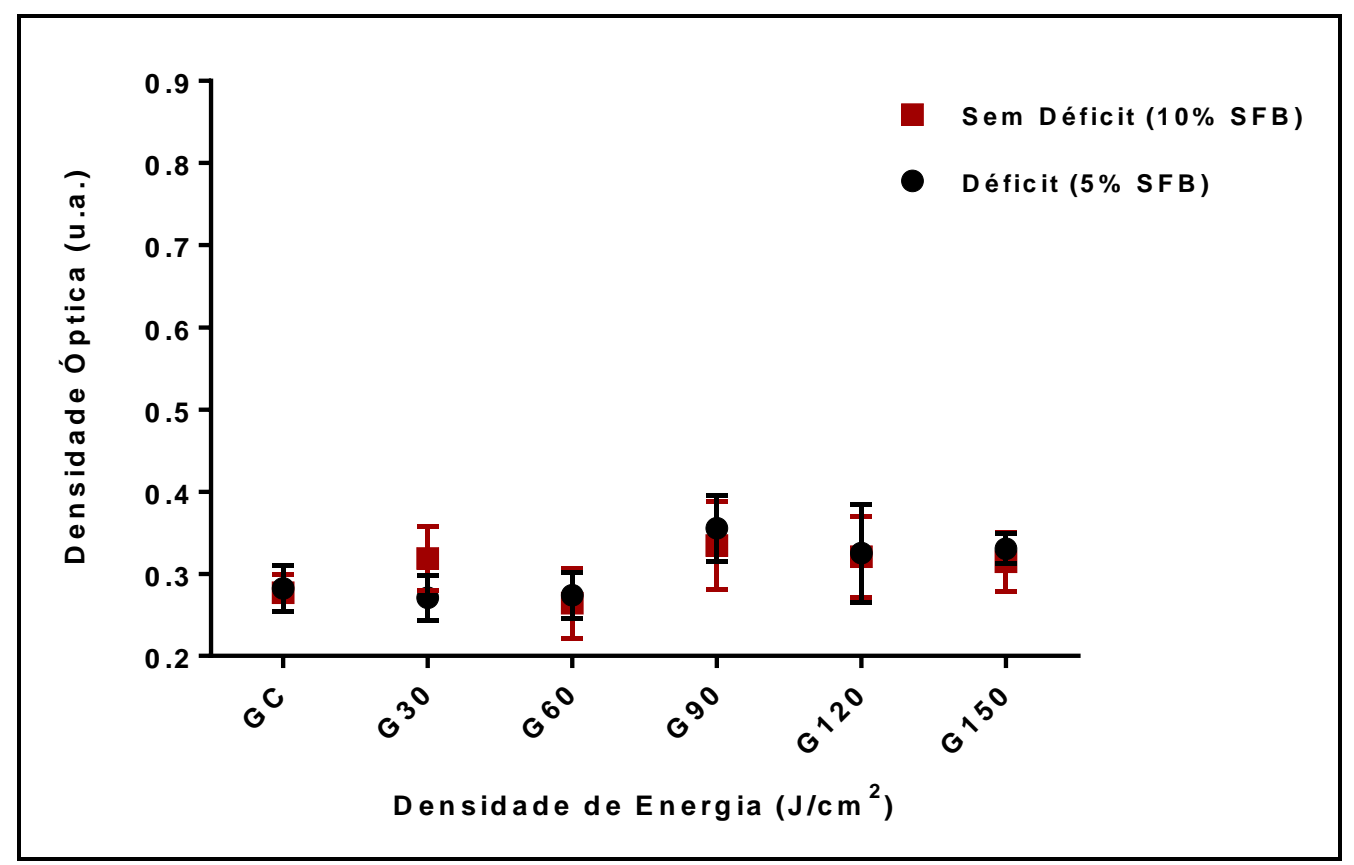

Figura 19 - Valores da média e desvio padrão correspondente à atividade mitocondrial medida pela densidade óptica (DO) para as células de melanoma murino B16F10 para as diferentes dosagens utilizadas no momento $24 \mathrm{~h}$. 


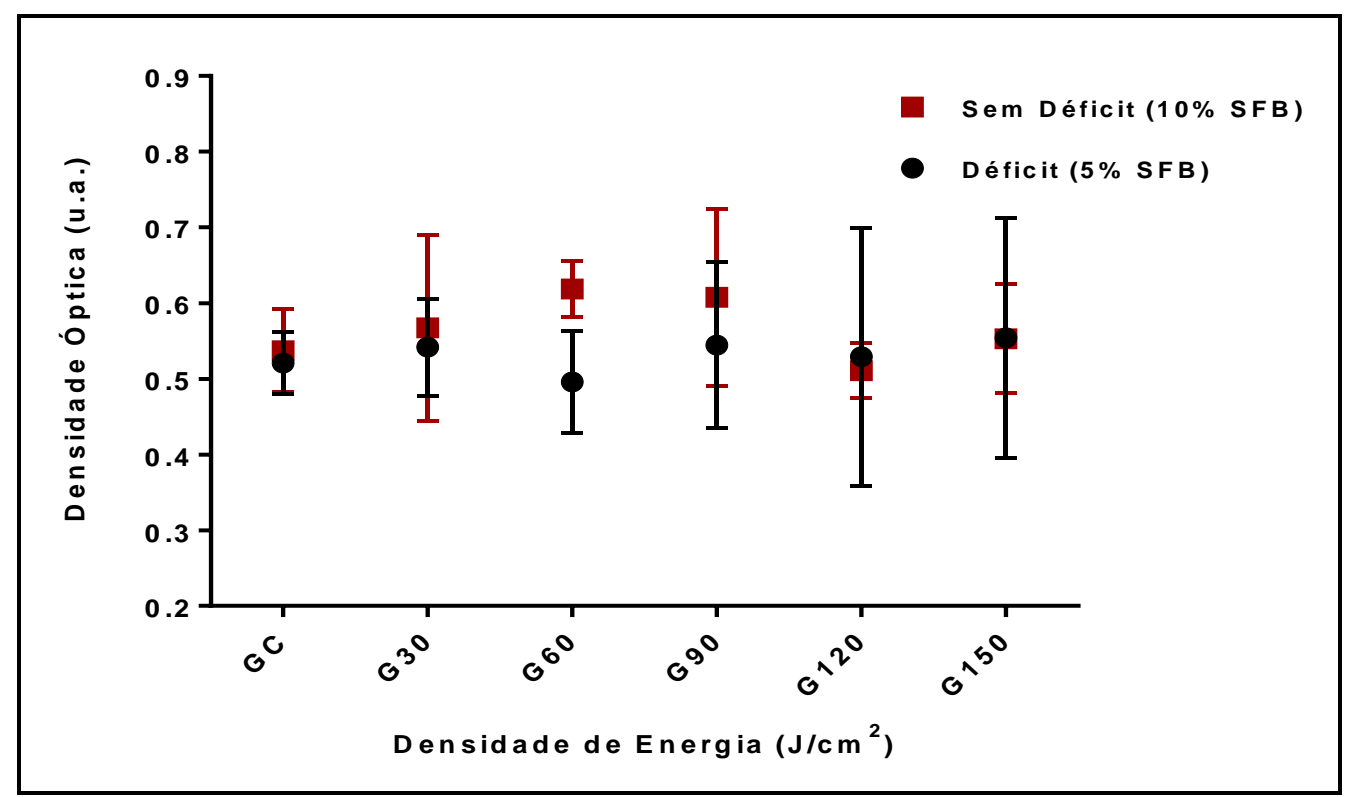

Figura 20 - Valores da média e desvio padrão correspondente à atividade mitocondrial medida pela densidade óptica (DO) para as células de melanoma murino B16F10 para as diferentes dosagens utilizadas no momento $48 \mathrm{~h}$.

Entretanto, na Figura 21, para o tempo de $72 \mathrm{~h}$, alguns resultados interessantes foram observados. Para densidades de energia acima de $60 \mathrm{~J} / \mathrm{cm}^{2}$, interessantemente as amostras em déficit nutricional (5\% de soro) mostraram um padrão de metaboslismo celular diferente das amostras sem déficit nutricional (10\% de soro). A atividade celular em cultivo com déficit foi significantemente mais alta comparada às culturas cultivadas sem déficit nutricional. 


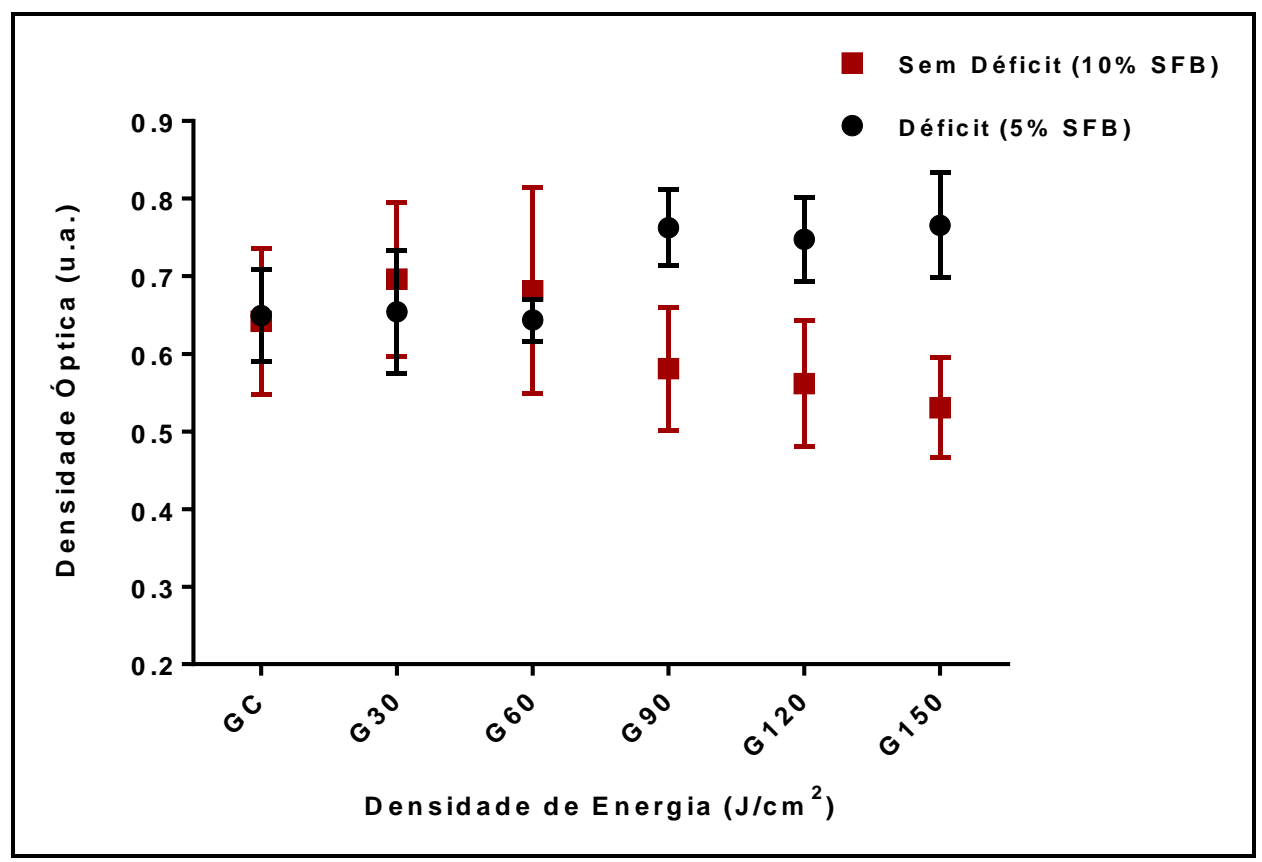

Figura 21 - Valores da média e desvio padrão correspondente à atividade mitocondrial medida pela densidade óptica (DO) para as células de melanoma murino B16F10 para as diferentes dosagens utilizadas no momento $72 \mathrm{~h}$.

A magnitude dos efeitos da TLBP na viabilidade celular da linhagem de melanoma B16F10 foi dependente do estado fisiológico da mesma antes da irradiação. Oçaña-Quero et al (57) analisaram os efeitos biológicos da irradiação laser $\mathrm{He}-\mathrm{Ne}$ em linhagem celular de mieloma (Sp2-Ag14) de ratos. Esses autores observaram um aumento de células nas fases $G_{0}-G_{1}$ do ciclo celular nos grupos irradiados com densidade de energia $\geq 8 \mathrm{~J} / \mathrm{cm}^{2}$, quando comparado com o grupo controle. Houve uma diminuição significativa na porcentagem de células na fase $S$ e nenhum efeito nas fases $\mathrm{G}_{2}-\mathrm{M}$ do ciclo celular.

A fase $G_{1}$ do ciclo celular é caracterizada pelo aumento da atividade celular, em decorrência da duplicação das organelas que precede a mitose (2). 0 aumento da atividade celular observado no presente estudo para as densidades 
acima de $60 \mathrm{~J} / \mathrm{cm}^{2}$ pode ter relação com fase do ciclo celular em que a cultura se encontrava.

Observa-se nas figuras 22 e 23 uma redução na média do número de células que migram com o aumento da dose utilizada na irradiação, embora, sem diferença estatisticamente significante. Os grupos que apresentaram um padrão de migração celular significantemente menor comparada ao grupo controle foram os grupos irradiados com a dose $\geq 90 \mathrm{~J} / \mathrm{cm}^{2}$.

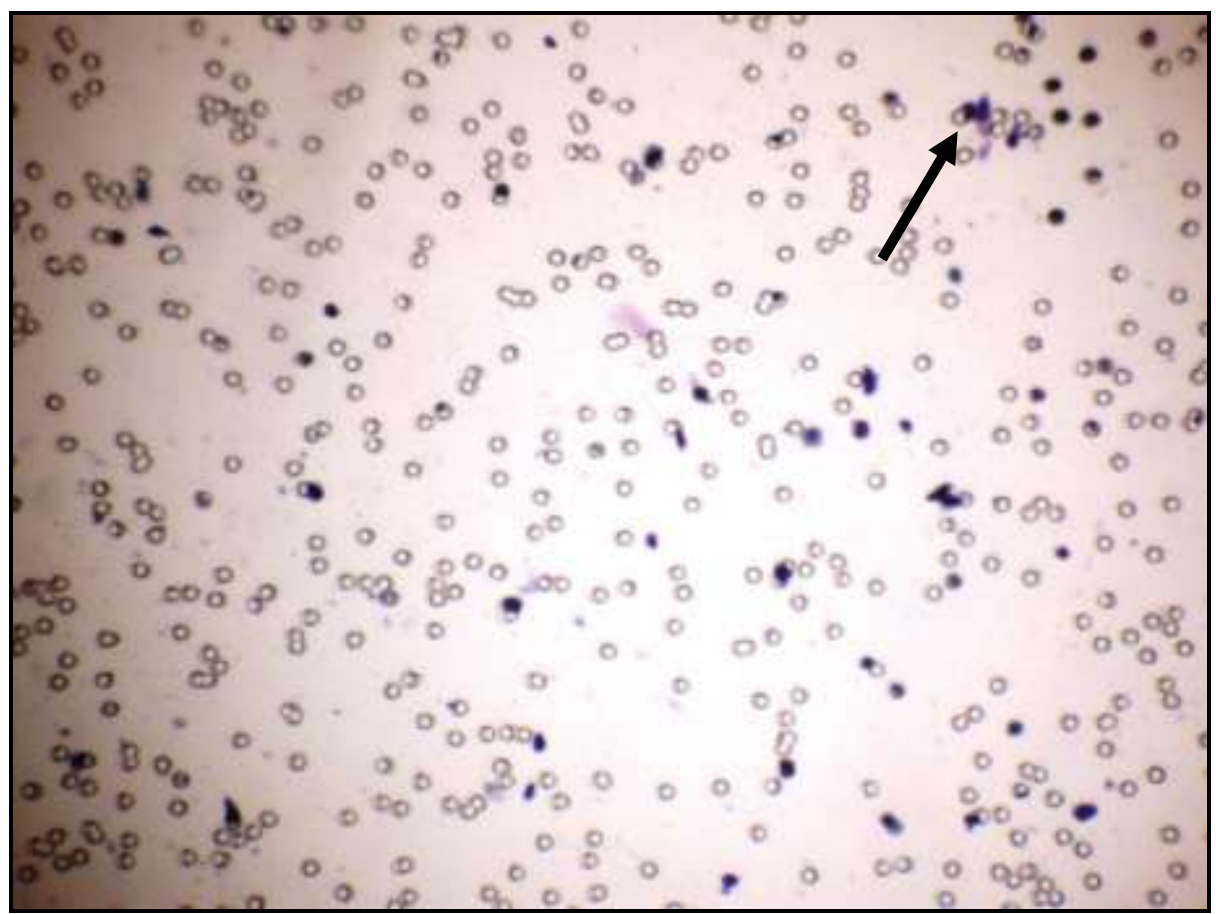

Figura 22 - Fotomicrografia de células de melanoma B16F10 que migraram observadas ao microscópio invertido. A seta aponta para células que migraram em busca do nutriente. 


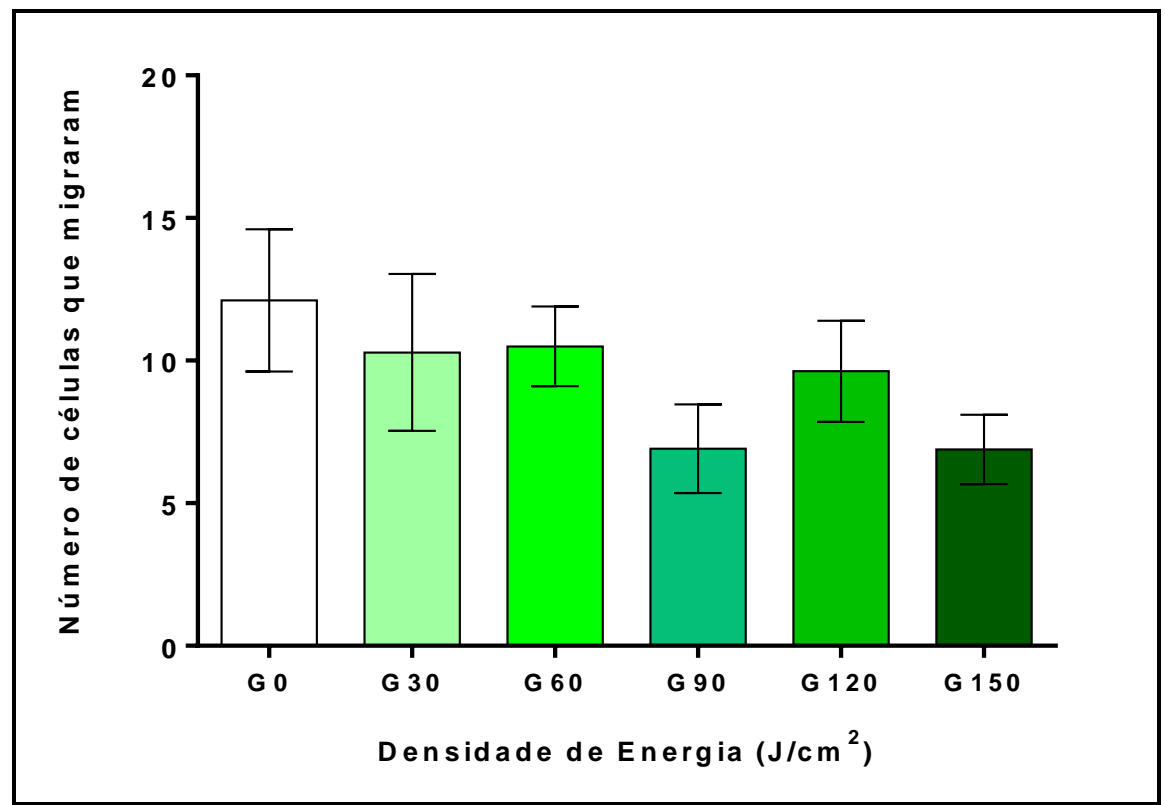

Figura 23 - Valores da média \pm erro padrão da medida correspondente ao número de células que migraram através do matrigel.

A invasão neoplásica e a formação de sítios metastáticos são os maiores desafios no tratamento das neoplasias malignas. O desenvolvimento de metástases depende da interação entre fatores do hospedeiro e características intrínsecas das células malignas. O ensaio de migração transwell é uma ferramenta importante para avaliação do comportamento quimotáxico de culturas celulares tumorais in vitro. No presente estudo observamos uma redução no número de células que migraram com o aumento da dose utilizada. ZHANG et al (69). estudaram os efeitos antineoplásicos de componentes do ácido salvianólico in vitro e in vivo em linhagem de melanoma B16F10. Eles relataram que os componentes do ácido salvianólico tem ação antineoplásica sobre a linhagem celular de melanoma, este efeito foi associado a modulação na expressão de metaloproteinases da matriz-2 e -9 (MMP-2 e MMP-9). DIAS et al (70). estudaram os efeitos do laser de baixa potência no metabolismo oxidativo e na expressão e atividade de metaloproteínas (MMP-2 e MMP-9) no músculo masseter de ratos. 
Segundo esses autores houve uma redução na expressão e atividade das metaloproteínases MMP-2 e MMP-9 em todos os grupos expostos à irradiação laser.

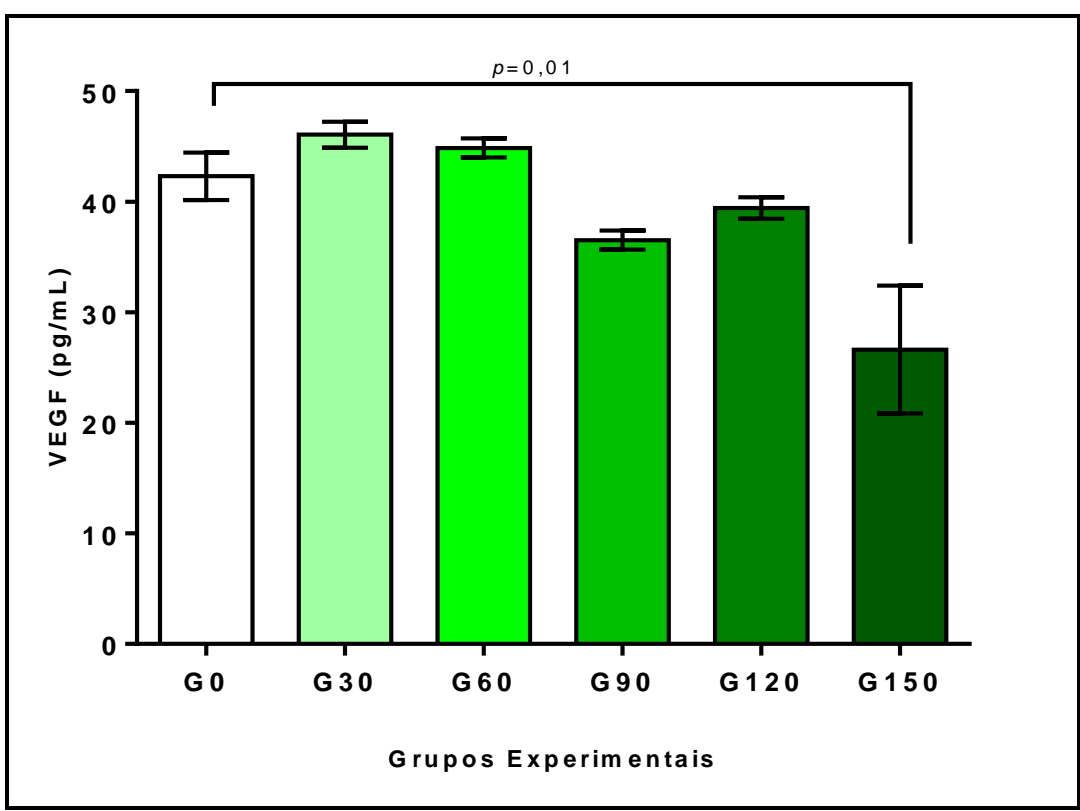

Figura 24 - Expressão de VEGF em linhagem de meleanoma murino (B16F10) irradiadas com diferentes densidadede energia.

Em análise geral e comparativa entre as diferentes doses, observou-se $24 \mathrm{~h}$ após a TLBP uma tendência de efeito inibitório da expressão de VEGF na linhagem celular B16F10 irradiadas com fluência de $90 \mathrm{~J} / \mathrm{cm}^{2}$ e $120 \mathrm{~J} / \mathrm{cm}^{2}$. No entanto, houve uma redução estatisticamente significante na expressão de VEGF no grupo irradiado com $150 \mathrm{~J} / \mathrm{cm}^{2}$ (Figura 24)

Os resultados por nós obtidos discordam dos encontrados por WU et al (71) que demostraram experimentalmente a capacidade da TLBP de emissão vermelha $\lambda=633 \mathrm{~nm}$, em fluência de $120 \mathrm{~J} / \mathrm{cm}^{2}$ em induzir a apoptose em células de adenocarcinoma de pulmão humano. Segundo esses autores, um dos 
possíveis mecamisnos envolvidos no processo de apoptose é a produção de espécies reativas de oxigênio.

Um aspecto importante é que as células tumorais continuam acumulando mutações em consequência da alta atividade metabólica, que podem alterar a expressão fenotípica das células tumorais desencadeando alterações nos receptores de membrana e vias de sinalização celular (72). Essas alterações podem interferir nos mecanismo de interação da luz com os tecidos biológicos. 


\section{CONCLUSÕES}

A irradiação com laser de baixa potência no comprimento de onda $\lambda=660 \mathrm{~nm}$, nas condições experimentais desse estudo, não promoveu mudanças no metabolismo celular que influenciaram a proliferação nos tempos de $24 \mathrm{~h}, 48 \mathrm{~h}$ e $72 \mathrm{~h}$, independente do estado nutricional.

Foi possível observar mudança no padrão de comportamento quimiotáxico da linhagem celular B16F10 de melanoma murino irradiadas com laser de emissão vermelha irradiadas com densidade de energia mais altas.

A expressão de VEGF nos sobrenadantes das culturas de células de melanoma murino B16F10 foi influenciada pela TLBP nos grupos irradidos com densidade de acima de $60 \mathrm{~J} / \mathrm{cm}^{2}$. 


\section{REFERÊNCIAS BIBLIOGRÁFICAS}

1 Estimativa 2012 - Incidência de câncer no Brasil. Disponível em: (2012). http://www.inca.gov.br/estimativa/2012/.

2 Alberts B, Johnson A, Lewis J, et al. Molecular Biology of the Cell. New York: $2010.1268 p$.

3 COTRAN, R. S.; KUMAR, V.; ROBBINS, S.T. Patologia estrutural e funcional. Rio de Janeiro: Guanabara Koogan, 1996.

4 Garbe, C.; Peris, K. et al. Diagnosis and treatment of melanoma. European consensus-based interdisciplinary guideline - Update 2012. European journal of cancer (Oxford, England : 1990), v. 48, n. 15, p. 2375-90, 2012.

5 Wang, S.Q.; Setlow, R. et al. Ultraviolet A and melanoma: a review. Journal of the American Academy of Dermatology, v. 44, n. 5, p. 837-46, 2001.

6 Palmieri, G.; Casula, M. et al. Issues affecting molecular staging in the management of patients with melanoma. Journal of cellular and molecular medicine, v. 11, n. 5, p. 1052-68, 2007.

7 Fartasch, M.; Diepgen, T.L. et al. The relationship between occupational sun exposure and non-melanoma skin cancer: clinical basics, epidemiology, occupational disease evaluation, and prevention. Deutsches Ärzteblatt international, v. 109, n. 43, p. 715-20, 2012.

8 Woodman, S.E.; Lazar, A.J. et al. New strategies in melanoma: molecular testing in advanced disease. Clinical cancer research : an official journal of the American Association for Cancer Research, v. 18, n. 5, p. 1195-200, 2012.

9 Castano, A.P.; Dai, T. et al. Low-level laser therapy for zymosan-induced arthritis in rats: Importance of illumination time. Lasers in surgery and medicine, v. 39, n. 6 , p. 543-50, 2007.

10 Albertini, R.; Aimbire, F. et al. COX-2 mRNA expression decreases in the subplantar muscle of rat paw subjected to carrageenan-induced inflammation after low level laser therapy. Inflammation research: official journal of the European Histamine Research Society ... [et al.], v. 56, n. 6, p. 228-9, 2007.

11 Yamaura, M.; Yao, M. et al. Low level light effects on inflammatory cytokine production by rheumatoid arthritis synoviocytes. Lasers in surgery and medicine, v. 41, n. 4, p. 282-90, 2009. 
12 Mognato, M.; Squizzato, F. et al. Cell growth modulation of human cells irradiated in vitro with low-level laser therapy. Photomedicine and laser surgery, v. 22, n. 6, p. 523-6, 2004.

13 Stein, a; Benayahu, D. et al. Low-level laser irradiation promotes proliferation and differentiation of human osteoblasts in vitro. Photomedicine and laser surgery, v. 23, n. 2, p. 161-6, 2005.

14 Lubart, R.; Wollman, Y. et al. Effects of visible and near-infrared lasers on cell cultures. Journal of photochemistry and photobiology. B, Biology, v. 12, n. 3, p. 305-10, 1992.

15 Ihsan, F.R.M. Low-level laser therapy accelerates collateral circulation and enhances microcirculation. Photomedicine and laser surgery, v. 23, n. 3, p. 289-94, 2005.

16 Schaffer, M.; Bonel, $H$. et al. $780 \mathrm{~nm}$ diode laser irradiation on blood microcirculation: preliminary findings on time-dependent $\mathrm{T} 1$-weighted contrastenhanced magnetic resonance imaging (MRI). ... of Photochemistry and ..., v. 54, n. 1, p. 55-60, 2000.

17 Salate, A.C.B.; Barbosa, G. et al. Effect of In-Ga-Al-P diode laser irradiation on angiogenesis in partial ruptures of Achilles tendon in rats. Photomedicine and laser surgery, v. 23, n. 5, p. 470-5, 2005.

18 Bjordal, J.M.; Johnson, M.I. et al. Low-level laser therapy in acute pain: a systematic review of possible mechanisms of action and clinical effects in randomized placebo-controlled trials. Photomedicine and laser surgery, v. 24, n. 2, p. 158-68, 2006.

19 Chow, R.T.; Barnsley, L. Systematic review of the literature of low-level laser therapy (LLLT) in the management of neck pain. Lasers in surgery and medicine, v. 37, n. 1, p. 46-52, 2005.

20 Laakso, E.-L.; Cabot, P.J. Nociceptive scores and endorphin-containing cells reduced by low-level laser therapy (LLLT) in inflamed paws of Wistar rat. Photomedicine and laser surgery, v. 23, n. 1, p. 32-5, 2005.

21 Ribeiro, M.S.; Silva, D.D.F.T. Da; et al. Effects of low-intensity polarized visible laser radiation on skin burns: a light microscopy study. Journal of clinical laser medicine \& surgery, v. 22, n. 1, p. 59-66, 2004.

22 Pinfildi, C.E.; Liebano, R.E. et al. Helium-neon laser in viability of random skin flap in rats. Lasers in surgery and medicine, v. 37, n. 1, p. 74-7, 2005.

23 Nascimento, P.M. do; Pinheiro, A.L.B. et al. A preliminary report on the effect of laser therapy on the healing of cutaneous surgical wounds as a consequence of an inversely proportional relationship between wavelength and intensity: 
histological study in rats. Photomedicine and laser surgery, v. 22 , n. 6, p. 5138, 2004.

24 Karu, T. Primary and secondary mechanisms of action of visible to near-IR radiation on cells. Journal of photochemistry and photobiology. B, Biology, $v$. 49, n. 1, p. 1-17, 1999.

25 Vladimirov, Y.A.; Osipov, A.N. et al. Photobiological Principles of Therapeutic Applications of Laser Radiation. v. 69, n. 1, 2004.

Karthein, W. and 1998 - - LLLT on Mitochondrial energy transfer.

27 Liebert, M.A.; Navratil, L. et al. Contraindications in Noninvasive Laser Therapy: Truth and Fiction. v. 20, n. 6, p. 341-343, 2002.

28 Kujawa, J.; Zavodnik, I.B. et al. Cell survival, DNA, and protein damage in B14 cells under low-intensity near-infrared $(810 \mathrm{~nm})$ laser irradiation. Photomedicine and laser surgery, v. 22, n. 6, p. 504-8, 2004.

29 Genot, M.-T.; Klastersky, J. Low-level laser for prevention and therapy of oral mucositis induced by chemotherapy or radiotherapy. Current opinion in oncology, v. 17, n. 3, p. 236-40, 2005.

30 Migliorati, C. a; Oberle-Edwards, L. et al. The role of alternative and natural agents, cryotherapy, and/or laser for management of alimentary mucositis. Supportive care in cancer: official journal of the Multinational Association of Supportive Care in Cancer, v. 14, n. 6, p. 533-40, 2006.

31 Carvalho, P. a G.; Jaguar, G.C. et al. Evaluation of low-level laser therapy in the prevention and treatment of radiation-induced mucositis: a double-blind randomized study in head and neck cancer patients. Oral oncology, v. 47, n. 12, p. 1176-81, 2011.

32 Miller, A.J.; Mihm, M.C. Melanoma. The New England journal of medicine, v. 355, n. 1, p. 51-65, 2006.

33 Durbec, F.; Martin, L. et al. Melanoma of the hand and foot: epidemiological, prognostic and genetic features. A systematic review. The British journal of dermatology, v. 166, n. 4, p. 727-39, 2012.

34 Egger, M.E.; McMasters, K.M. et al. Unique prognostic factors in acral lentiginous melanoma. American journal of surgery, 2012.

35 Bennàssar, A.; Ishioka, P. et al. Surgical treatment of primary melanoma. Dermatologic therapy, v. 25, n. 5, p. 432-42, 2012.

36 Zbytek, B.; Carlson, J.A. et al. Current concepts of metastasis in melanoma. Expert review of dermatology, v. 3, n. 5, p. 569-585, 2008. 
37 Jahanshahi, P.; Nasr, N. et al. Malignant melanoma and radiotherapy: past myths, excellent local control in 146 studied lesions at Georgetown University, and improving future management. Frontiers in oncology, v. 2, n. November, p. 167, 2012.

38 Sivendran, S.; Glodny, B. et al. Melanoma Immunotherapy. p. 620-642, 2010.

39 Papetti, M.; Herman, I.M. Mechanisms of normal and tumor-derived angiogenesis. American journal of physiology. Cell physiology, v. 282, n. 5, p. C947-70, 2002.

40 Shibuya, M. Vascular Endothelial Growth Factor and its Receptor System: Physiological Functions in Angiogenesis and Pathological Roles in Various Diseases. Journal of Biochemistry, p. 1-18, 2012.

41 Johnson, K.E.; Wilgus, T. a Multiple roles for VEGF in non-melanoma skin cancer: angiogenesis and beyond. Journal of skin cancer, v. 2012, p. 483439, 2012.

42 Nakano, J.; Kataoka, H. et al. Low-level laser irradiation promotes the recovery of atrophied gastrocnemius skeletal muscle in rats. Experimental physiology, v. 94, n. 9, p. 1005-15, 2009.

43 Corazza, A.V.; Jorge, J. et al. Photobiomodulation on the angiogenesis of skin wounds in rats using different light sources. Photomedicine and laser surgery, $v$. 25, n. 2, p. 102-6, 2007.

44 Tuby, H.; Maltz, L. et al. Modulations of VEGF and iNOS in the rat heart by low level laser therapy are associated with cardioprotection and enhanced angiogenesis. Lasers in surgery and medicine, v. 38, n. 7, p. 682-8, 2006.

45 Feng, J.; Zhang, Y. et al. Low-power laser irradiation (LPLI) promotes VEGF expression and vascular endothelial cell proliferation through the activation of ERK/Sp1 pathway. Cellular signalling, v. 24, n. 6, p. 1116-25, 2012.

46 Cristofanilli, M.; Charnsangavej, C. et al. Angiogenesis modulation in cancer research: novel clinical approaches. Nature reviews. Drug discovery, v. 1, n. 6 , p. 415-26, 2002.

47 Redondo, P.; Bandrés, E. et al. Vascular endothelial growth factor (VEGF) and melanoma. $\mathrm{N}$-acetylcysteine downregulates VEGF production in vitro. Cytokine, v. 12 , n. 4, p. 374-8, 2000.

48 Vihinen, P.P.; Hilli, J. et al. Serum VEGF-C is associated with metastatic site in patients with malignant melanoma. Acta oncologica (Stockholm, Sweden), v. 46, n. 5, p. 678-84, 2007.

49 Fidler, I.J. hypothesis revisited. v. 3, n. June, p. 1-6, 2003. 
50 Huang, Y.-Y.; Chen, A.C.-H. et al. Biphasic dose response in low level light therapy. Dose-response : a publication of International Hormesis Society, v. 7, n. 4, p. 358-83, 2009.

51 Karu, T.I.; Pyatibrat, L. V; et al. Cellular effects of low power laser therapy can be mediated by nitric oxide. Lasers in surgery and medicine, v. 36, n. 4, p. 30714, 2005.

52 Karu, T.I.; Pyatibrat, L. V; et al. Elementary processes in cells after light absorption do not depend on the degree of polarization: implications for the mechanisms of laser phototherapy. Photomedicine and laser surgery, v. 26, n. 2, p. 77-82, 2008.

53 Coombe, a R.; Ho, C.T. et al. The effects of low level laser irradiation on osteoblastic cells. Clinical orthodontics and research, v. 4, n. 1, p. 3-14, 2001.

54 Castro, J.L.F. de; Pinheiro, A.L.B. et al. The effect of laser therapy on the proliferation of oral KB carcinoma cells: an in vitro study. Photomedicine and laser surgery, v. 23, n. 6, p. 586-9, 2005.

55 Frigo, L.; Luppi, J.S.S. et al. The effect of low-level laser irradiation (In-Ga-AlAsP - $660 \mathrm{~nm}$ ) on melanoma in vitro and in vivo. BMC cancer, v. 9, p. 404, 2009.

56 Kreisler, M.; Christoffers, A.B. et al. Low-level $809 \mathrm{~nm}$ GaAIAs laser irradiation increases the proliferation rate of human laryngeal carcinoma cells in vitro. Lasers in medical science, v. 18, n. 2, p. 100-3, 2003.

57 Ocaña-Quero, J.M.; Perez de la Lastra, J. et al. Biological Effect of HeliumNeon (He-Ne) Laser Irradiation on Mouse Myeloma (Sp2-Ag14) Cell Line In Vitro. Lasers in Medical Science, v. 13, n. 3, p. 214-218, 1998.

58 Pinheiro, A.L.B.; Carneiro, N.S. et al. Effects of low-level laser therapy on malignant cells: in vitro study. Journal of clinical laser medicine \& surgery, $v$. 20, n. 1, p. 23-6, 2002.

59 Powell, K.; Low, P. et al. The effect of laser irradiation on proliferation of human breast carcinoma, melanoma, and immortalized mammary epithelial cells.

Photomedicine and laser surgery, v. 28, n. 1, p. 115-23, 2010.

60 Renno, a C.M.; McDonnell, P. a; et al. The effects of laser irradiation on osteoblast and osteosarcoma cell proliferation and differentiation in vitro. Photomedicine and laser surgery, v. 25, n. 4, p. 275-80, 2007.

61 Schaffer, M.; Sroka, R. et al. Biomodulative effects induced by $805 \mathrm{~nm}$ laser light irradiation of normal and tumor cells. Journal of photochemistry and photobiology. B, Biology, v. 40, n. 3, p. 253-7, 1997. 
62 Werneck, C.E.; Pinheiro, A.L.B. et al. Laser light is capable of inducing proliferation of carcinoma cells in culture: a spectroscopic in vitro study. Photomedicine and laser surgery, v. 23, n. 3, p. 300-3, 2005.

63 Cle, O.L.A. Low-level laser therapy in management of postmastectomy lymphedema. Breast, p. 90-94, 2006.

64 Ahmed Omar, M.T.; Abd-El-Gayed Ebid, A. et al. Treatment of postmastectomy lymphedema with laser therapy: double blind placebo control randomized study. The Journal of surgical research, v. 165, n. 1, p. 82-90, 2011.

65 Carati, C.J.; Anderson, S.N. et al. Treatment of postmastectomy lymphedema with low-level laser therapy: a double blind, placebo-controlled trial. Cancer, v. 98, n. 6, p. 1114-22, 2003.

66 Lequin, R.M. Enzyme immunoassay (EIA)/enzyme-linked immunosorbent assay (ELISA). Clinical chemistry, v. 51, n. 12, p. 2415-8, 2005.

67 Almeida-Lopes, L.; Rigau, J. et al. Comparison of the low level laser therapy effects on cultured human gingival fibroblasts proliferation using different irradiance and same fluence. Lasers in surgery and medicine, v. 29, n. 2, p. 179-84, 2001.

68 Marques, M.M.; Pereira, A.N. et al. Effect of low-power laser irradiation on protein synthesis and ultrastructure of human gingival fibroblasts. Lasers in surgery and medicine, v. 34, n. 3, p. 260-5, 2004.

69 Zhang, L.; Chen, L. et al. Danshensu has anti-tumor activity in B16F10 melanoma by inhibiting angiogenesis and tumor cell invasion. v. 643, p. 195-201, 2010.

70 Jose, F.; Vicentini, D.C. et al. Effects of Low-Level Laser Therapy on the Oxidative Metabolism and Matrix Proteins in the Rat Masseter Muscle. v. 29, n. 10, p. 677-684, 2011.

71 Wu, S.; Xing, D. et al. High fluence low-power laser irradiation induces mitochondrial permeability transition mediated by reactive oxygen species. Journal of cellular physiology, v. 218, n. 3, p. 603-11, 2009.

72 Loeb, L.A.; Loeb, K.R. et al. Multiple mutations and cancer. v. 100, n. 3, p. 776-781, 2003. 